\title{
Molecular Characterization and Functional Analysis of a Necrosis- and Ethylene-Inducing, Protein-Encoding Gene Family from Verticillium dahliae
}

\author{
Bang-Jun Zhou, ${ }^{1,2}$ Pei-Song Jia, ${ }^{1,3}$ Feng Gao, ${ }^{3}$ and Hui-Shan Guo ${ }^{1}$ \\ ${ }^{1}$ State Key Laboratory of Plant Genomics and National Center for Plant Gene Research, Institute of Microbiology, Chinese \\ Academy of Sciences, Beijing 100101; ${ }^{2}$ Graduate University of Chinese Academy of Sciences, Beijing 100049; ${ }^{3}$ The Key \\ Laboratory of Prevention and Control for Oasis Crop Disease, Shihezi University, Shihezi, Xinjiang, China
}

Submitted 23 December 2011. Accepted 7 March 2012.

Verticillium dahliae Kleb. is a hemibiotrophic, phytopathogenic fungus that causes wilt disease in a wide range of crops, including cotton. Successful host colonization by hemibiotrophic pathogens requires the induction of plant cell death to provide the saprophytic nutrition for the transition from the biotrophic to the necrotrophic stage. In this study, we identified a necrosis-inducing Phytophthora protein (NPP1) domain-containing protein family containing nine genes in a virulent, defoliating isolate of $V$. dahliae (V592), named the VdNLP genes. Functional analysis demonstrated that only two of these $V d N L P$ genes, $V d N L P 1$ and $V d N L P 2$, encoded proteins that were capable of inducing necrotic lesions and triggering defense responses in Nicotiana benthamiana, Arabidopsis, and cotton plants. Both VdNLP1 and VdNLP2 induced the wilting of cotton seedling cotyledons. However, gene-deletion mutants targeted by $V d N L P 1, V d N L P 2$, or both did not affect the pathogenicity of $V$. dahliae $V 592$ in cotton infection. Similar expression and induction patterns were found for seven of the nine $V d N L P$ transcripts. Through a comparison of the conserved amino acid residues of VdNLP with different necrosis-inducing activities, combined with mutagenesis-based analyses, we identified several novel conserved amino acid residues, in addition to the known conserved heptapeptide GHRHDWE motif and the cysteine residues of the NPP domain-containing protein, that are indispensable for the necrosis-inducing activity of the VdNLP2 protein.

Phytopathogens from various taxonomic origins among bacteria, fungi, and oomycetes have been shown to secrete and inject structurally unrelated effectors into the apoplast and cytoplasm of plants to establish infection and to suppress the host defenses (Chisholm et al. 2006; Kamoun 2006; Lindeberg et al. 2008). In contrast, many bacteria, fungi, and oomycetes produce proteins that trigger leaf necrosis and immunity-associated responses in various plants. A 24-kDa protein that causes necrosis and induces ethylene biosynthesis (necrosis- and ethylene-inducing protein [Nep1]) in many dicotyledonous plants was first detected in culture filtrates of the vascular wilt fungus Fusarium oxysporum (Bailey 1995).

Corresponding author: H.-S. Guo; Telephone: +010-64847989; Fax: +01064847989; E-mail: guohs@im.ac.cn

* The $\boldsymbol{e}$-Xtra logo stands for "electronic extra" and indicates that one supplementary figure and one supplementary table are published online.
An emerging group of proteins being identified by the presence of a common necrosis-inducing Phytophthora protein (NPP1) domain (Fellbrich et al. 2000; Fellbrich et al. 2002) have collectively been named the Nepl-like proteins (NLP). NLP constitute a superfamily of proteins that are produced by various phytopathogenic microorganisms, comprising both prokaryotic and eukaryotic organisms (Bae et al. 2006; Gijzen and Nurnberger 2006; Kamoun 2006; Pemberton and Salmond 2004). Common to all NLP proteins is a conserved heptapeptide motif, GHRHDWE, and an amino-terminal register of conserved cysteine residues. Based on the number of cysteine residues, NLP can be classified as type I or type II, which possess either two or four cysteine residues, respectively (Gijzen and Nurnberger 2006). NLP proteins have also been shown to trigger many characteristic defense responses in dicotyledonous plants but not in monocotyledonous plants (Fellbrich et al. 2000, 2002; Motteram et al. 2009; Qutob et al. 2006; Schouten et al. 2008; Veit et al. 2001). Recently, the crystal structure of an NLP from the phytopathogenic oomycete Pythium aphanidermatum $\left(\mathrm{NLP}_{\text {Pya }}\right)$ has been determined. $\mathrm{NLP}_{\text {Pya }}$ mutant protein analyses reveal that identical structural properties (the two conserved cysteine residues from type I NLP, the NLP $\mathrm{P}_{\text {Pya }}$ D104 residue, and the heptapeptide motif GHRHDWE) are required to cause plasma membrane permeabilization and cytolysis in plant cells (Ottmann et al. 2009). NLP-mediated phytotoxicity and plant defense gene expression were further shown to share identical fold requirements, suggesting that toxin-mediated interference with host integrity triggers plant immunity-associated responses (Ottmann et al. 2009).

Utilizing the comparative analysis of the distribution and copy number of NLP-encoding genes containing the NPP1 domain in sequenced filamentous fungal genomes, only a single NLP-encoding gene, $M g N L P$, was found in the plant-pathogenic fungus Mycosphaerella graminicola (Motteram et al. 2009) but four NLP homologues were found in the rice blast fungus Magnaporthe grisea (Dean et al. 2005). Recently, eight NLP homologues were predicted in a pathogenic fungus, Verticillium dahliae, isolated from lettuce (Klosterman et al. 2011). One of these homologues, identified from cotton isolate $V$. dahliae $\mathrm{Vd}-8$ and named VdNEP, was proven to induce the formation of necrotic lesions, trigger the production of reactive oxygen species, and induce the expression of pathogenesisrelated $(P R)$ genes in plants (Wang et al. 2004).

$V$. dahliae Kleb. is a phytopathogenic fungus that causes wilt disease in a wide range of crops (Pegg 1989), including cotton. The fungus is widespread in most cotton-growing areas, in- 
cluding China (Xia et al. 1998), the Americas (Bowman 1999; Schnathorst and Mathre 1966), and the Mediterranean regions (Koroleva et al. 2001), and is a major threat to cotton production. Substances secreted by $V$. dahliae cause vascular discoloration and wilt symptoms associated with disease development in cotton (Buchner et al. 1982; Keen et al. 1972; Nachmias et al. 1982, 1985, 1987). Both the low and high molecular weightsecreted phytotoxic metabolites behave as elicitors, inducing phytoalexin formation as well as the formation of phytotoxins that trigger wilt symptoms. On cotton cotyledons and leaves, the bacterially expressed His-VdNEP protein induced dehydration and wilting, similar to the symptoms caused by a crude preparation of V. dahliae elicitors (Wang et al. 2004). However, it is not known whether all eight of the predicted $V$. dahliae NLP homologues are functionally similar to VdNEP, possessing the same necrotic activities and acting as elicitors to trigger plant defense responses, and the mechanisms by which these proteins contribute to $V$. dahliae virulence and infection are likewise unknown.

In this study, we cloned and identified nine potential NPP1 domain-containing cDNAs from a virulent, defoliating strain of $V$. dahliae (V592) that was isolated from cotton in Xinjiang, China. These potential NLP homologues were named $V d N L P 1$ to $V d N L P 9$. We found that two type I VdNLP proteinsVdNLP1, which is homolog to VdNEP-encoding protein from $V$. dahliae Vd-8 (Wang et al. 2004), and VdNLP2-but not the other seven type I and II $V d N L P$-encoding proteins were capable of inducing necrotic lesions and triggering defense responses in plants. Both VdNLP1 and VdNLP2 induced the wilting of cotton seedling cotyledons but were dispensable for $V$. dahliae pathogenicity. Mutagenesis-based analyses for the conserved amino acids found several novel indispensable, conserved sites for necrotic activity. The necrotic and elicitor activities of the VdNLP from $V$. dahliae, a hemibiotrophic phytopathogenic fungus, against cotton plants are discussed.

\section{RESULTS}

\section{Cloning and identification of an NPP1 domain-containing} protein family from $V$. dahlia.

Eight NLP genes in $V$. dahliae were predicted by a recent comparative genomics study (Klosterman et al. 2011). Based on the genome sequences of VdLs.17, a $\mathrm{V}$. dahliae isolate from lettuce, eight potential NPP1 domain-containing protein coding sequences and one short homologue lacking the part of the sequence upstream of the NPP1 domain were identified (VDAG_04701.1, VDAG_01995.1, VDAG_02984.1, VDAG_ 03497.1, VDAG_04550.1, VDAG_04834.1, VDAG_06993.1, VDAG_08022.1, and VDAG_09117.1), and we obtained these nine potential NPP1 domain-containing cDNAs from the V592 strain of $V$. dahliae. Blastp analyses showed high amino acid sequence identity of each NPP1 domain-containing protein between VdLs.17 and V592. The protein VDAG_04701.1 was a homologue of VdNEP identified from the V. dahliae Vd-8, a cotton isolate (Wang et al. 2004), and, hence, is named a $V$. dahliae NEP1-like protein (VdNLP1). The remainder of these proteins were sorted by homology levels and referred to as VdNLP2 to VdNLP9 (Fig. 1). The amino acid sequence relationships are shown in Figure 1 and were determined by neighbor analysis with 1,000 bootstrap replications between each of these nine VdNLP and nine other plant pathogen-derived NLP for which the necrosis- and ethylene-inducing activities were confirmed. The nine VdNLP were sorted into four distinct groups (Fig. 1). A comparison of the amino acid sequence revealed that a type I, with two conserved cysteine residues, VdNLP1 (VDAG_04701.1) had a sequence identity of 51\% with the BeNEP1 from Botrytis elliptica (Staats et al. 2007)
(Fig. 1). Another type I VdNLP2 (VDAG_01995.1) had 59\% with the MgNLP from Mycosphaerella graminicola (Motteram et al. 2009) and 56\% with the BeNEP2 from B. elliptica (Staats et al. 2007) and formed a big group with five other NLP from Phytophthora parasitica, P. infestans, P. sojae, Pythium aphanidermatum, and Bacillus halodurans (Fig. 1). VdNLP3 was also type I but resided with VdNLP6, which had only one cysteine residue in a separate branch with the NLP from $F$. oxysporum (Fig. 1). In contrast, VdNLP4, VdNLP 5, VdNLP 7, VdNLP 8, and VdNLP 9 resided on a separate branch and contained two to six additional cysteines. Two of these cysteines were conserved among these VdNLP proteins (Fig. 1).

\section{Identification of necrosis-inducing and elicitor activities of VdNLP.}

To determine the necrotic-inducing activities of the VdNLP, the open reading frame sequences corresponding to the nine VdNLP were inserted into the binary plant transformation vector pBI121 for Agrobacterium spp.-mediated plant expression (Ying et al. 2010). The plants were observed for up to 14 days postinfiltration for the presence of local necrotic lesions. Necrotic lesions were clearly observed on Nicotiana benthamiana leaves 7 days postinfiltration with Agrobacterium spp. containing pBI-VdNLP1 or pBI-VdNLP2 but not on leaves with Agrobacterium spp. containing other pBI-VdNLP or the pBIGUS control plasmid (Fig. 2A). The triggering of the production of reactive oxygen species (such as $\mathrm{H}_{2} \mathrm{O}_{2}$ ) in leaves infiltrated with pBI-VdNLP1 and pBI-VdNLP2, but not pBIVdNLP3 or the control vector, was also detected within 2 days of infiltration (Fig. 2B), preceding the onset of lesion formation. Consistent with the previous report that VdNEP from the $V$. dahliae Vd-8 (the homologue of VdNLP1) had the ability to induce necrotic cell death in $N$. benthamiana (Wang et al. 2004), our results also revealed that, in addition to the VdNLP1 (the homologue of VdNEP), $V$. dahliae contains a

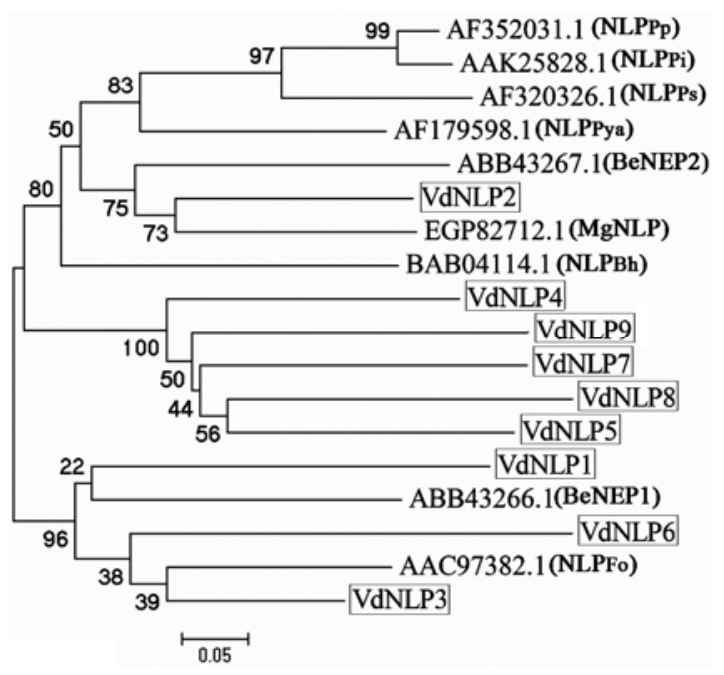

Fig. 1. Phylogenetic relationship of the necrosis-inducing Phytophthora protein (NPP1) domain-containing protein family from Verticillium dahliae and nine other plant pathogen-derived necrosis- and ethylene-inducing protein (Nep1)-like proteins (NLP). The analysis was performed using the package MEGA4 (Tamura et al. 2007). Percent bootstrap values (1,000 replicates) are shown above the forks. Accession numbers of species: AF352031.1 ( $\left.\mathrm{NLP}_{\mathrm{Pp}}\right)$ (Phytophthora parasitica), AAK25828.1 $\left(\mathrm{NLP}_{\mathrm{Pi}}\right)(P$. infestans), AF320326.1 ( NLP $\left._{\mathrm{Ps}}\right)$ (P. sojae), AF179598.1 ( NLP $_{\text {Pya }}$ ) (Pythium aphanidermatum), ABB43267.1 (BeNEP2) and ABB43266.1 (BeNEP1) (Botrytis elliptica), EGP82712.1 (MgNLP) (Mycosphaerella graminicola), BAB04114.1 $\left(\mathrm{NLP}_{\mathrm{Bh}}\right)$ (Bacillus halodurans), and AAC97382.1 ( $\left.\mathrm{NLP}_{\mathrm{Fo}}\right)$ (Fusarium oxysporum). Names of VdNLP are framed. 


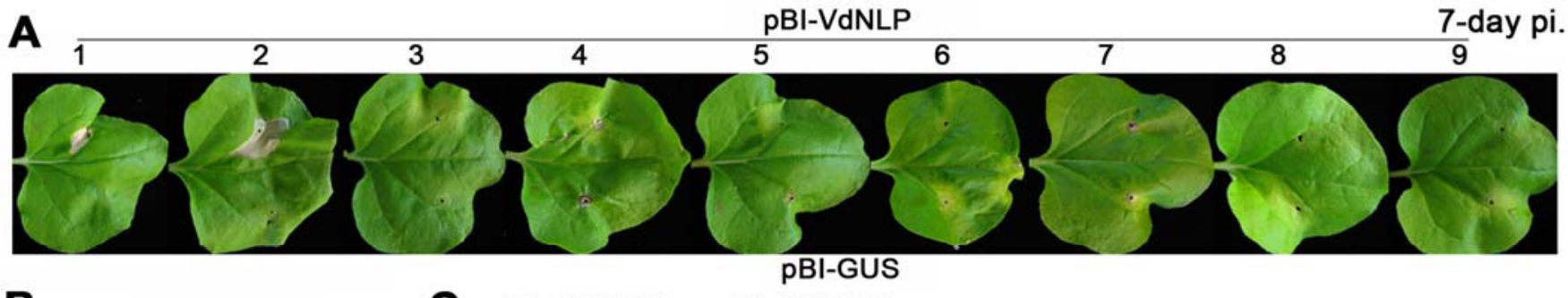

B 2-day pi.

pBI-VdNLP1 -VdNLP2

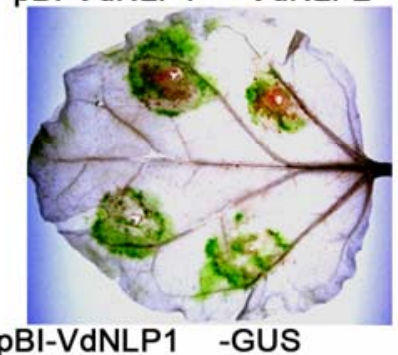

pBI-VdNLP1 -GUS
C

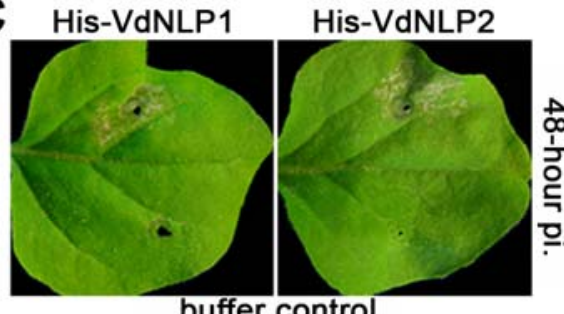

D His-VdNLP1 His-VdNLP2

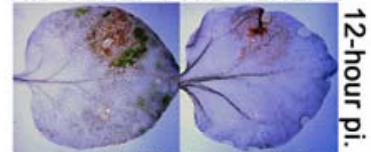

$\mathbf{E}$ control VdNLP1 VdNLP2

- $\overline{1248} \overline{1248} \overline{1248}$

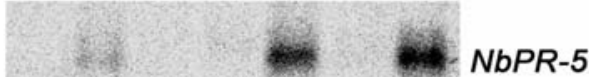

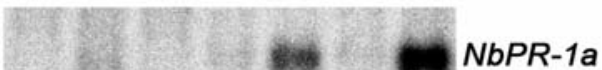

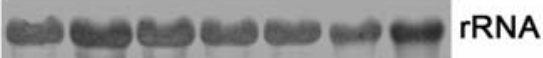

$\mathbf{F}$

control VdNLP1 VdNLP2 VdNLP3 VdNLP4

buffer control

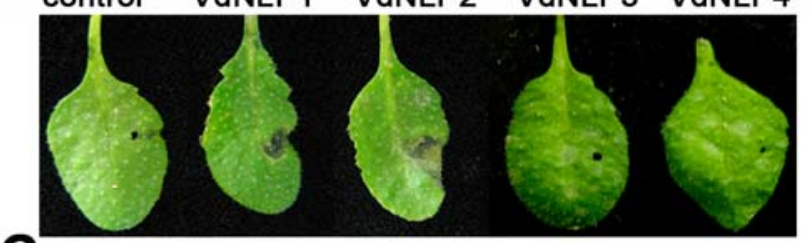

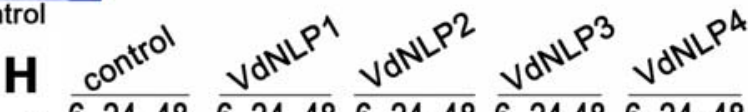

- $\overline{62448} \overline{62448} \overline{62448} \overline{62448} \overline{62448}$ hours

G

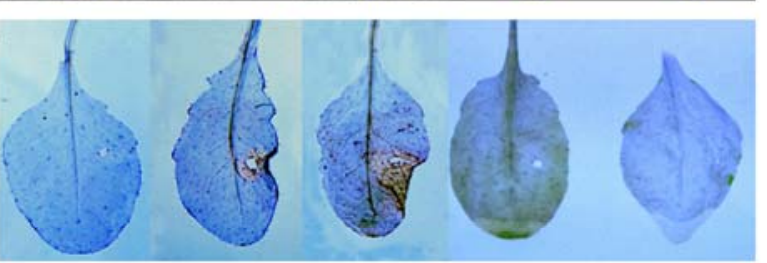

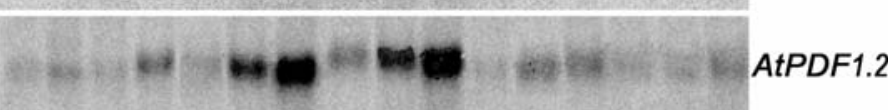

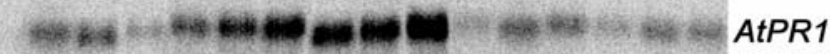

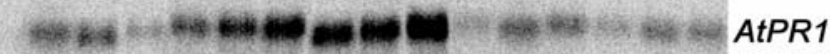

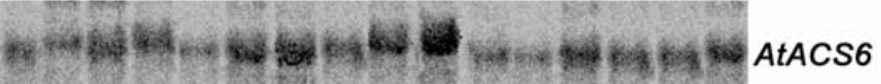

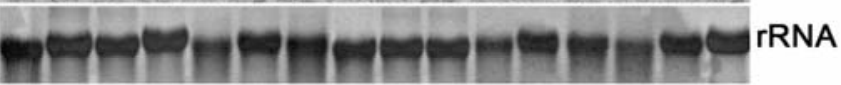

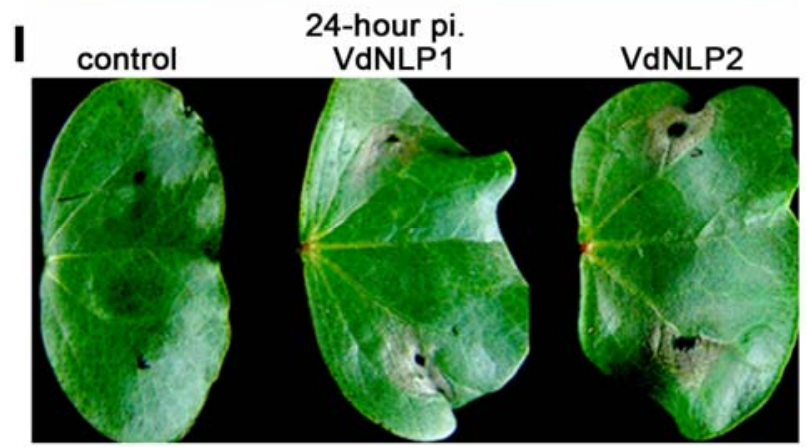

J

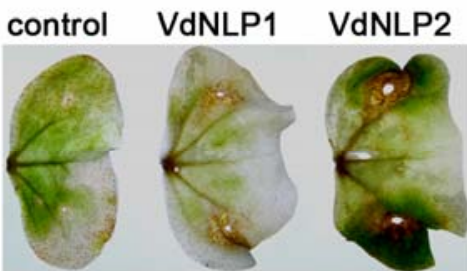

L control

Toxins VdNLP1

VdNLP2
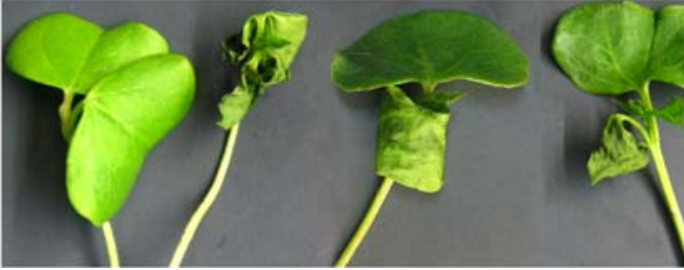

5-hour pi.
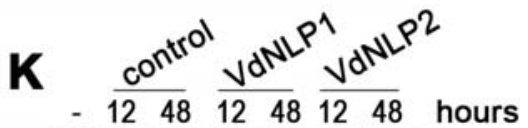

Fig. 2. Identification of necrosis-inducing and elicitor activities of Verticillium dahliae necrosis- and ethylene-inducing protein (Nep1)-like proteins (VdNLP). Detection of necrosis induction of VdNLP by Agrobacterium spp. infiltration in A, Nicotiana benthamiana leaves or by His-tagged protein infiltration in $\mathbf{C}$, Nicotiana benthamiana; $\mathbf{F}$, Arabidopsis; and $\mathbf{I}$, cotton leaves. B, D, G, and $\mathbf{J}$, Detection of production of reactive oxygen species by staining with 3,3-diaminobenzidine solution for $8 \mathrm{~h}$. E, H, and $\mathbf{K}$, RNA gel blot analysis of induction of plant defense response genes expression. ${ }^{32} \mathrm{P}-$ labeled genespecific DNA probes were used. Methylene blue-stained rRNAs are shown as mRNA loading controls. L, Detection of leaf wilt caused by the infiltration of each Escherichia coli-expressed His-tagged fusion protein or the crude toxins into the hypocotyls of cotton seedlings. 
second NPP1 domain-containing protein, VdNLP2, that also has necrosis-inducing activity. However, another type I protein, VdNLP3, and all of the type II VdNLP were incapable of inducing cell death when transiently expressed in $N$. benthamiana.

The necrosis-inducing activities of VdNLP1 and VdNLP2 were further verified with purified proteins. All nine VdNLP proteins were each expressed in Escherichia coli as a Histagged fusion protein (His-VdNLP1 to His-VdNLP9). The purified His-VdNLP proteins were obtained in good agreement with the calculated size of the fusion protein (Supplementary Fig. S1A). Within $48 \mathrm{~h}$ of the infiltration of the purified His-VdNLP1 and His-VdNLP2 into $N$. benthamiana leaves at a concentration as low as $0.05 \mu \mathrm{g} / \mu \mathrm{l}(0.265$ pmol/liter), necrosis appeared around the infiltrated sites but not around the areas infiltrated with the other seven HisVdNLP proteins and control buffer (Fig. 2C). The production of reactive oxygen species in the leaves by His-VdNLP1 and His-VdNLP2 but not by the other seven His-NLP proteins within $12 \mathrm{~h}$ of infiltration was also detected (Fig. 2D). The elicitor activities of VdNLP1 and VdNLP2 in triggering the expression of defense-related genes were then examined. RNA gel blot analysis showed that the $P R$ genes $N b P R-1 a$ and $N b P R-5$ in $N$. benthamiana were induced at $48 \mathrm{~h}$ postinfiltration (hpi) with His-VdNLP1 and His-VdNLP2 but not with the control buffer treatment (Fig. 2E).

To further assess the impact of VdNLP1 and VdNLP2 on ethylene biosynthesis and the salicylic acid (SA)- and jasmonic acid (JA)-dependent defense signaling pathways, the His-tagged fusion proteins were applied to a well-defined Arabidopsis system. Both His-VdNLP1 and His-VdNLP2, but not the other seven His-VdNLP proteins, induced necrotic cell death and the production of reactive oxygen species in Arabidopsis (Fig. 2F and G). The abilities of the VdNLP to trigger the expression of PRI and PDF1.2, the marker genes of the SA- and JA-dependent defense signaling pathways, respectively (Glazebrook 2001; Hammond-Kosack and Jones 1996; Wang et al. 2004), and ACS6, encoding 1-aminocyclopropane-1-carboxylate synthase for ethylene biosynthesis (Jennings et al. 2001; Sato and Theologis 1989; Wang et al. 2004), were examined for the three of type I VdNLP (VdNLP1 to VdNLP3) and one type II, VdNLP4. An RNA gel blot analysis showed strongly triggered expression of the AtPRI and AtPDF1.2 transcripts at 6 or 24 hpi with the His-VdNLP1 and His-VdNLP2 proteins but not for His-VdNLP3 or His-VdNLP4, compared with the control buffer treatment (Fig. 2H). An increased expression of the ACS6 transcript at $24 \mathrm{hpi}$ with His-VdNLP1 or His-VdNLP2 was also detected in comparison with the control and with His-VdNLP3 and His-VdNLP4 treatment (Fig. 2H). Our results revealed that the ethylene biosynthesis pathway and the SA- and JA-dependent defense signaling pathways were activated by both VdNLP1 and VdNLP2 but not by VdNLP that did not have necrotic activities. It appeared that VdNLP2 triggered a quicker response in the induction of SA- and JAdependent defense signaling than did VdNLP1 in Arabidopsis.

We next examined the necrosis-inducing and elicitor activity of VdNLP1 and VdNLP2 in the natural host of V. dahliae, cotton plants. Purified His-tagged proteins were applied to cotton cotyledons at 10 days postgermination. The His-VdNLP1 and His-VdNLP2 but not the other seven His-VdNLP proteins induced necrosis and the production of reactive oxygen species in cotton (Fig. 2I and J). His-VdNLP1- and His-VdNLP2induced expression of the $P R$ gene Omsotin was also detected at $12 \mathrm{hpi}$ and increased at $48 \mathrm{hpi}$ by RNA gel blot analysis (Fig. 2K). Previous studies showed that the transcription levels of genes encoding enzymes of the gossypol pathway were greatly increased upon elicitation with a crude preparation of
$V$. dahliae elicitors, followed by increased accumulation of gossypol and related sesquiterpene phytoalexins (Liu et al. 1999; Luo et al. 2001). Therefore, the induction of the cotton $(+)-\delta$-cadinene synthase $C A D 1-C 1$, a sesquiterpene cyclase and the key gene of the gossypol pathway (Meng et al. 1999), was examined in response to VdNLP1 and VdNLP2 treatment. A strong induction of the $C A D 1-C 1$ transcript was detected at 48 hpi in both protein treatments by RNA gel blot analysis (Fig. $2 \mathrm{~K})$. Consistent with the above observation, VdNLP2 triggered a faster response in the induction of the $C A D 1-C 1$ transcript in cotton than did VdNLP1.

Leaf wilt is the key symptom of cotton plants infected with $V$. dahliae. VdNEP and various components of the glycoproteins secreted by $V$. dahliae were shown to cause cotton leaf wilting (Wang et al. 2004). Therefore, E. coli-expressed HisVdNLP1 and His-VdNLP2, as well as $V$. dahliae-secreted toxins prepared from the culture of V592 in the liquid CzapekDox medium, were compared site by site, assessing the wiltinducing activities caused by the infiltration of each protein or the crude toxins into the hypocotyls of cotton seedlings. Leaf wilting was observed in one of the cotyledons for the treatment with each of the two VdNLP proteins within $5 \mathrm{hpi}$, and more depauperated leaves were observed in VdNLP2-infiltrated seedlings (Fig. 2L), consistent with the rapid induction of the plant defense response by VdNLP2. At this time point, both cotyledons were completely blasted in the crude toxins-infiltrated cotton seedling but grew well with the control buffer infiltration (Fig. 2L).

\section{Identification of additional conserved amino acids required for the necrosis-inducing activity of VdNLP2.}

The crystal structure of the NLP from the phytopathogenic oomycete $P$. aphanidermatum $\left(\mathrm{NLP}_{\text {Pya }}\right)$ and $\mathrm{NLP}_{\text {Pya }}$ mutant protein analyses reveal that several conserved amino acids (two conserved cysteines; another highly conserved aspartic acid residue, NLP Pya $_{\text {D93 }}$; and a heptapeptide motif, GHRH DWE) are required for plasma membrane permeabilization and cytolysis in plant cells (Ottmann et al. 2009). Our above infiltration assay in $N$. benthamiana revealed that only VdNLP1 and VdNLP2, but not the other seven members of the NPP1 domain-containing protein family had necrosis-inducing and elicitor activity. Sequence alignment showed that VdNLP6-9 contained an imperfect heptapeptide motif, with one or two of the conserved amino acids differing from the conserved heptapeptide GHRHDWE motif of VdNLP1, VdNLP2, and the six other plant pathogen-derived NLP for which the necrosis and ethylene-inducing activities were confirmed (Fig. 3). The short VdNLP6 also lacked the upstream sequence, including the two conserved cysteine and NLP Pya $_{\text {D }}$ 93 residues. However, another type I protein, VdNLP3, and the type II proteins VdNLP4 and VdNLP5, which also lacked the necrosis-inducing and elicitor activities, contained the complete conserved heptapeptide GHRHDWE motif, the two conserved cysteines, and the NLP Pya D93 residue (Fig. 3), suggesting a requirement for additional conserved amino acids for the activity. The $\mathrm{N}$ terminal region was reported to be required for NLP-induced necrosis and plant defense activation (Fellbrich et al. 2002). Therefore, several conserved amino acid residues in the $\mathrm{N}$ terminus of VdNLP1 and VdNLP2 that were lacking in VdNLP3 to VdNLP9 were examined for their requirement for necrosis induction. The residues in question were individually exchanged in VdNLP2 (Fig. 3), and the necrosis-inducing activity of the VdNLP2 mutant proteins was assessed via Agrobacterium spp.-mediated infiltration (Fig. 4). The conserved heptapeptide ${ }^{126} \mathrm{GHRHDWE}{ }^{132}$ motif and the two cysteine (C64 and C90) and aspartic acid (D119) corresponding to the NLP $_{\text {Pya }}$ D93 residues (C64S, C90S, D119A, G126S, H127D, R128A, 
VdNLP9

VdNLP8

VdNLP7

VdNLP6

VdNLP5

VdNLP4

VdNLP3

VdNLP2

VdNLP1

NLPPp

NLPPi

NLPPs

NLPBh

NLPFo

NLPpya

VdNLP2

VdNLP9

VdNLP8

VdNLP7

VdNLP6

VdNLP5

VdNLP4

VdNLP3

VdNLP2

VdNLP1

NLPPp

NLPpi

NLPps

NLPBh

NLPFo

NLPPya

VdNLP2

VdNLP9

VdNLP8

VdNLP7

VdNLP6

VdNLP5

VdNLP4

VdNLP3

VdNLP2

VdNLP1

NLPPp

NLPPi

NLPPs

NLPBh

NLPFo

NLPPya

VdNLP2

VdNLPG

VdNLP8

VdNLP7

VdNLP6

VdNLP5

VdNLP4

VdNLP3

VdNLP2

VdNLP1

NLPPp

NLPpi

NLPPs

NLPBh

NLPFo

NLPPya

VdNLP2
MLFLQNIAVVTAMVLSVP---STASVMRRQNNSSRILSESPALEPIVNGHDFAYYFEVKFQPLVDFDTD MAHASF SPGLWQPALHR I VLL LVL YLALVHPSNCSVIQRRAAPPQK--LPKRATEDDLRYQPALDFDTD MP SLRT ASFSA VAA L LL L PA V IA T PLPDT P T T K I RRDL RQPL GGSAW SEQEKW C- - - - PALDYDTD MW T CRFMAP - - - - - - - - LADL VP -- T Y GFL APL T DG-- - - M- -- LFS V GLLALA ALPSFGAVIQARQDDPENPPRDPQPP--PPGPIFGRAPDLDKRFQPALDFDTD MQH TLLSTAALL G-- - - - AL SAVN-ASPAP I LRRDI IT------ALPGNADE IENKFQPI LDFDTD M------VSK I FS - T LAS I AL VAA GPV SLRA V VPHDS LNPVTQR-VQTGA I GDA I A KFNPLLHI-AN MSP-----SL I S I VTWLAAA S T LAAPLLESRA V INHDA VVGFPQT -VPSGVSGQLMLKFKPYLKV-FN MHP - TRWELD I MLPSA VF SVFALVGSALAQQPPK VNHDS INPVRDT - L G--PNGDMI RKFQPL LH I - AH MN-- - - - VL TFL I AAAVSLAVVQA----- DV I SHDAVVPFAQP-TAT T T EQKAGVKFKPQIHI -SN MN------ I LQLFASAAAAL T VAHA------DV I SHDA VIPFAQP T T T T T T EQKAG I KFKPQ I H I - SN

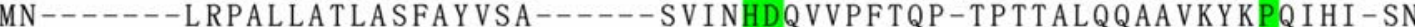
MMR-- - - FV I GFLLS I LAS I SLVSP---ANAAVI DHDKVVGFEEV-TPT T I TQKVAKRFQPYL TV-ST MHPQT IFNAL VALAAT GMAAPSEALNNLHAR - A VVNHDSLNPVKKT - IEGGA I GAAI DRWQPLLHI - AD MVR-----FVSALL LAAAGVLA STNA------AVINHDAVPVWPQP-EPADATQALAVRFKPQLDV-VN MSP-----SLI S IVTWLAAA S ST LAAPLLESRA V INHDAVVGFPQT -VPSGVSGQLMLKFKPYLKV-FN
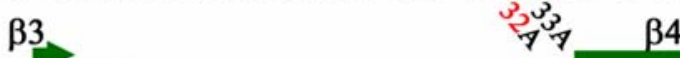

$\beta 5$

SCYSVPAMTMDGT A SEGLSPS-D-D-V-GPCRPRSALDRTNVYVRGRCNRGWCAFVYAY YFQMDWAWSW SCYNVPA I GCDGK I AEGLEPDGT TKDYRDLADPD----NTNVYSRQRCNSGWCAYMY DY YFEKDHADI G SCYNT VA I SPSGQLNAGQDENKPAGE I L GWCRKEVHLQQTN I YVRSRCNNGWCVHMY DY YFEADF---G SCYNVPAI GPNGDLA I GMYPFEWPPQ-AG-CRNEEMLDRGNVYSRQRCNNGYCVIFYAYYFQKDTATPGCYNT AA I DPD GN INPGKGATGT-PQ-GD-CRDPPQLENSNVYSRRRCNNGVCA IMYEY YFEKDQSVSG GCQPY TA VNDAGDT SGGLQDSGN-IS-AE-CRDQSK---GQT Y ARAK V VNGQLA IMY SF YMPKDQP IAG GCVPFPAVNAGGDT GGGLAT SGS-SN-GG-CSSSA----GQVYARAGSYNGANA ILYAWYMPKDAPSSC GCQPYSAVNTRGEVNAGLQDSGT-TA-GG-CKET SK---GQT YARSMT LNGQFG IMYAW YWPKDQPADC GCHPYPAVDANGNTSGGLKPT GS-SS-AG-CKGSGY--GSQVYGRVAT YNGVYA IMY SW Y FPKDSPVTC GCHPYPA VDADGNTSGGLNPTGS-SS-AG-CKGSGY--GSQIYGRVAT YNGVFA IMYSWYFPKDSPLTG GCHPYPAVDNNGNT SG GLNPT GS-ES-AG-CKGSGY--GTQI Y GRAVKYQGVYAFMY SWYMPKDETLTG GCVPFPA VDADGNT SGGLAPTGP-HN-GG-CSSHI----GQVYSRSTWHNGVWA IMYAW YFPKDSPSPG GCQPYTAVDTNGNVSGGLQDSGS-KT-GG-CKDT SK---GQTYARAAMHNGKLA IMY AW Y WPKDQPADG GCQPYPA VDPQGNT SG GLKPSGS-QA-AA-CRDMSK---AQVYSRSGT YNG YYA I M Y SW YMPKDSPST G GCVPFPAVNAGGDT GGGLAT SGS-SN-GG-CSSSA----GQVYARAGS YNGANA I L YAWYMPKDAPSSG

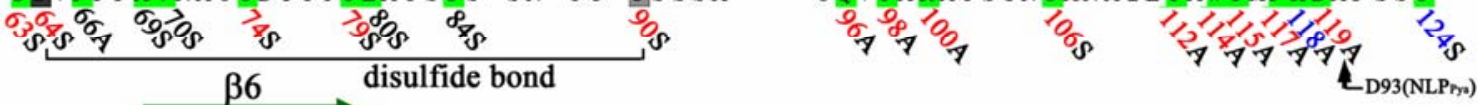

PVSG YNHRHDWEHVVVWAKE------GKVRGVSVSQHGGYESRVAEDQT SV-AMHPK----VVFHKDGAR - - - AHKHDWEH I I VWV T D-- - DRT KNKK Y ACV SQHGEW LCHPEDK VLW KDEHPK VP I MA--------- W GAHRHDWEH I A VWVQ------HGQLKF VS I SQHGKWD IR I L D GRT AAPRFEHGTHPK VVYHKDGAL ---- IAHRHDFEN I VVFVDDPA VNP IPA I L GGAA SGHGEY K T T ATPDV--E-GDSVK----VEYFTTF-L --- I DGHRHDWEH I A VWVRQ-- - SDSFVTHVA V SQHKGYDIRENSQ I TW TAAENGKPA - - I VYHKDS IL -SFA GGHRHDWENVVVFAR------GDT IVRVAP SCHGGYGGA SNEFPAD--GTSPQ----MVYHKDSAG -NVA GGHRHDWENVVI F VDDPAANAAP GLLGGAA SGHGEYKKT ATPDR--E-GDSVK----VEYFTTFP---- LGHRHDWEGAVVWLSS-AAADAT - VVGVAA SAHGDFDVRPAADVSFA-GARPK----LGYRSTWP-NLA SGHRHDWENVVI WFNSNNANQAG - ILRGAA SGHGDYKKVNNPQRNNN-- -NLH----VEYFT SLG---- LGHRHDWEHVVVWVDDI K LDSPS - I I A VSPSAHS GYN I Y YPPESNT IDG YSAK----VDY SSSW VV

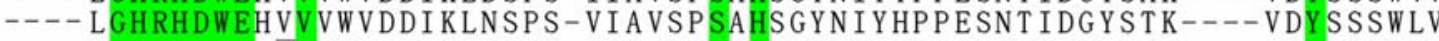
- - - LGHRHDWEACVVWVDDI AAS SPK - IVALSASAHSGYNKYYPPSSSYFSGNSAK-- - I DY SSSYVV - - - L GHRHDWE G IVVW VDNPANPSPQ-LL S IAY SQHGNF Y NVAP T DRN T R-EQRPL-- - I RY SHAWP-NLV SGHRHDWENVVVFI DNYQSPGAT - LYAAAA SGHGDYKKT KNPQRSGN---NVM----AEYFTSFG---- I GHRHDWEN V VVWLDN--AASAN-IVALSASAHSGYKKSFPADKSYLDG ITAK----ISYKSTWP---- LGHRHDWEGAVVWLSS-AAADAT - VVGVAASA HGDFDVRPAADVSFA-GARPK-- - -LGYRSTWP-

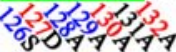

T-HCFRFAKDSDDYEGQENERG I WI RGGT VSM-L-LMPSDWQDKFRSHGWGSAHMAWANEDDFT GHLVKS T-HAFRW AND-----GDEPPENHWK SWRWGVGAG-LIEWERMPDNLRK TL SAKNWGAAEMAVRDKDGSDTNHELQFT AT - - - TGK T Y P I SDWDAMPQAARDA-LET - - - - T DFGS ANVPFKDANFDSNLAK AAL T-HCFRF GSG----ADA GGP GPENHKNQW I T GPL-LGYFGW DT VERDRML THNWEAGS I A I KNENFAENT-HCFRFAND----ADI GGVENFSGSFYKSPLVGWLSWPNEGLRQTMLG-AFSGGVGPKLDDEFAGKLGTNHELQFTAT - - - TGK T Y P I SDWDAMPQAARDA-LET - - - - T DFGSANVPFKDANFDSNLAK AAL VNHQMVFT AD----QGGEQP LVAWESLTPAARAA-LQN------TDFGSANVPLKDGNFASNLQKAALKNHELQFK T S-- - PGRTYW IW DWDRMDT T VQGA-LNR------ADFGSANCP FNNNNFERNMRAAF-I NHA LDST T D - - -AGETQDL I MWDQL T DAARTA-LEN----- T DFGDANVPMK DGNFL T K VGNAYYA I NHA LDST TD--- AGETQNLI MWDQLTDAARTA-LEN------T DFGDANVPMKDGNFLTK VGNAY YA I NHA LSAT ST - - - AGETQP L I MWDQLT DAARRA-LED------ T DFGDANVPFKDANFQTKLGNAYYA LNHSLW I HDQ----VGGTQPL I GWDDLT PAARHA-LNT------T DFGAANVPFNDHNF INNLRKAWYR KNHELQFK TS--- - PGRT YW I Y DWAAMT PAAQKG-LI T GPSGDPNKPWGSANVPF I DANFGNNLNKAWSLDHELGFT T S--- AGKQQPLI QWEQMTQAARDA-LES----- T DFGNANVPFK S-NFQDKLVKAFFQ VNHQMVFTAD----QGGEQPLVAWESLTPAARAA-LQN------T DFGS ANVPLKDGNFASNLQKAAL- 
H129A, D130A, W131A, and E132A) were also individually exchanged in VdNLP2 for controls. Consistent with the previous report (Ottmann et al. 2009), mutant proteins C64S, C90S, and D119A, as well as H127D, D130A, and E132A in the heptapeptide motif of VdNLP2, failed to cause leaf necrosis (Fig. 4). Additionally, the necrotic activities were reduced in the mutant proteins G126S, R128A, and H129A and were unchanged in W131A in the heptapeptide motif compared with those of the wild-type VdNLP2 protein (Fig. 4). The mutant proteins Y112A, W114A, Y115A, and P117A failed to induce leaf necrosis. The necrotic activities were reduced by K118A or G124S (Fig. 4). The requirement of the conserved tryptophan (W114, corresponding to W88 in NLP Pya $_{\text {a }}$ closed to the D93) for VdNLP2 biological activity might explain why VdNLP3, which lacked only this conserved tryptophan but contained all of the other conserved residues, failed to induce leaf necrosis. Together with the observation that the necrotic activities of
VdNLP2 were abolished in Y112A, W114A, Y115A, and P117A and reduced in K118A and G124S mutant proteins, our results suggested that the conserved residues Y112, W114, Y115, P117, and K118 in the close vicinity of D119 in the crystal structure $\beta 5$-strand (Ottmann et al. 2009) were also necessary for VdNLP2 necrotic activity. Additional mutations in the N-terminal conserved residues located in the crystal structure $\beta$-strands and loop regions were created (Fig. 3). The mutant proteins H32A, P56A, G63S, G74S, G79S, Q96A, Y98A, R100A, and G106S failed to induce leaf necrosis. The necrotic activities were not changed by mutations D33A, P66A, A69S, V70S, L80S, and G84S (Fig. 4). Our results indicated that additional $\mathrm{N}$-terminal conserved residues, such as those in $\beta 4$-strand, and G74 and G79 located between two conserved cysteine residues that form the bisulfide bond (Ottmann et al. 2009), were also important for the VdNLP2 necrotic activity (Fig. 4).

\section{$\leftarrow$}

Fig. 3. Alignment of the amino acid sequence of the necrosis-inducing Phytophthora protein (NPP1) domain-containing protein family from Verticillium dahliae and six other plant pathogen-derived necrosis- and ethylene-inducing protein (Nep1)-like proteins (NLP). Conserved Cys-64 and Cys-90 (formation of the disulfide bond) (Ottmann et al. 2009) and other Cys are highlighted in gray; conserved amino acids in NLP for which have necrosis- and ethyleneinducing activity are highlighted in green. Residues individually exchanged in VdNLP2 are marked below the VdNLP2 amino acid sequence. Each related amino acid mutant protein that failed to cause leaf necrosis is labeled in red, reduced necrosis-inducing activity is in blue, unchanged necrotic activity is in black. Regions of several $\beta$-strands of structure elements of $\mathrm{NLP}_{\mathrm{Pya}}$ (Ottmann et al. 2009) are shown with green arrows.

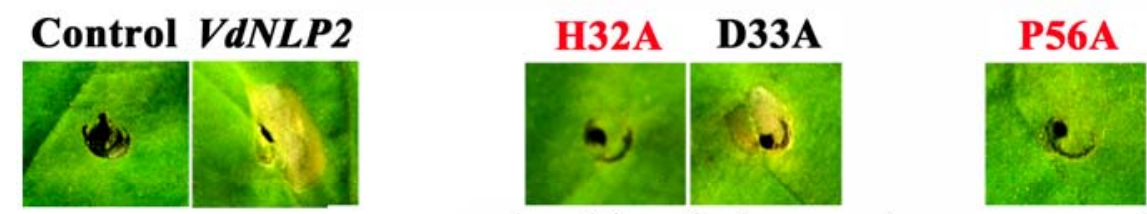

conserved residues in loop region conserved residue in $\beta 2$
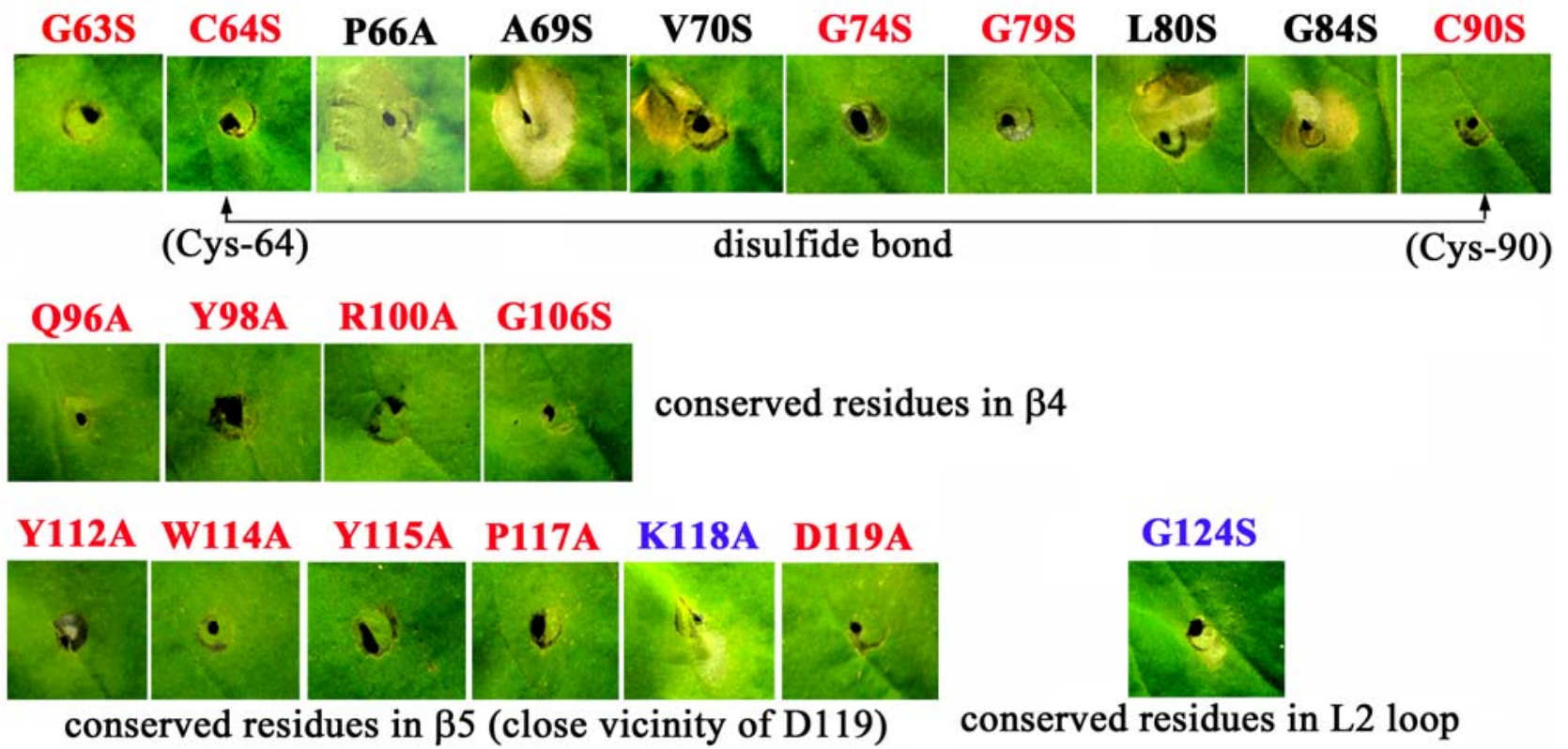

conserved residues in L2 loop

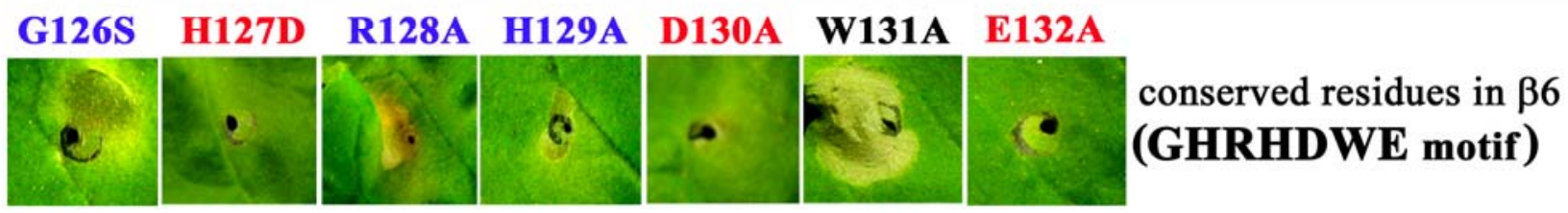

Fig. 4. Detection of necrosis-inducing ability of Verticillium dahliae necrosis- and ethylene-inducing protein (Nep1)-like protein (VdNLP)2 mutant proteins by Agrobacterium spp. infiltration in Nicotiana benthamiana leaves. Location of each amino acid related to NLP Pya is indicated. Each related amino acid mutant protein that failed to cause leaf necrosis is labeled in red, reduced necrosis-inducing activity is in blue, unchanged necrotic activity is in black. Photographs were taken at 7 days postinfiltration. 
Analysis of expression of the $V d N L P$ transcripts.

The expression levels of the $V d N L P 1$ and $V d N L P 2$ transcripts were first examined in wild-type V592. Both of the $V d N L P$ transcripts were primarily expressed in the hyphae but also at a lower level in the spores collected from liquid Czapek-Dox medium (Fig. 5A). Increased expression of both VdNLP transcripts was detected in the liquid medium at 7 days postincubation (dpi) (Fig. 5A). However, when fresh cotton roots were added into the liquid medium, an increased expression of both $V d N L P$ transcripts was detected at 3 and 5 dpi (Fig. 5A). Increased accumulation of $V d N L P 1$ and $V d N L P 2$ transcripts were further confirmed by quantitative real-time reverse-tran-

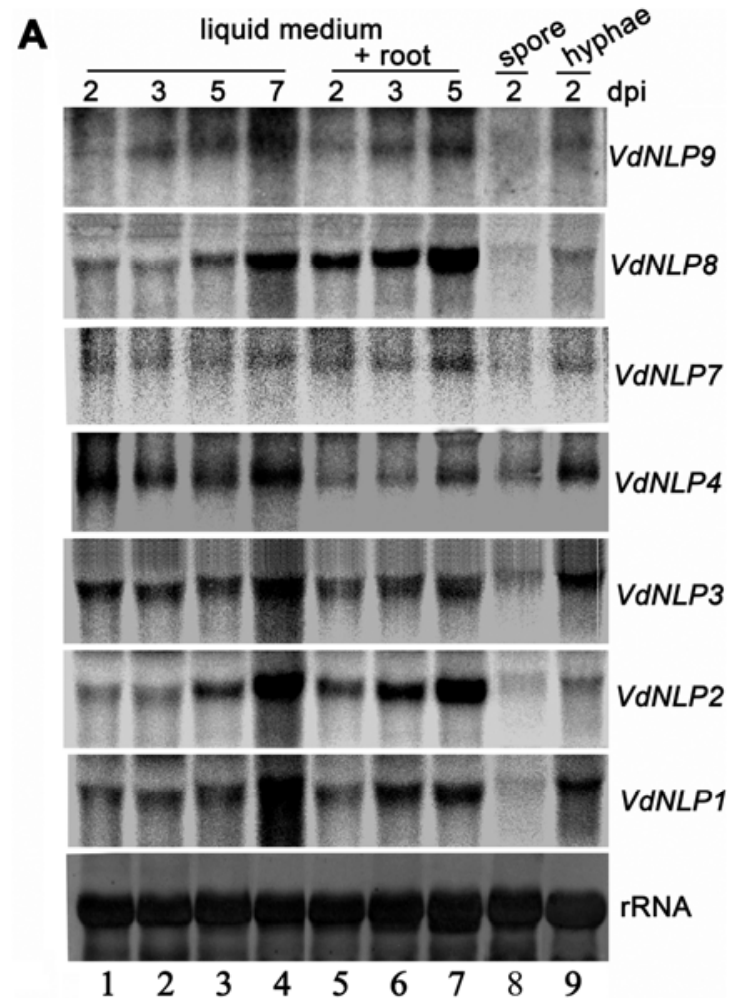

B

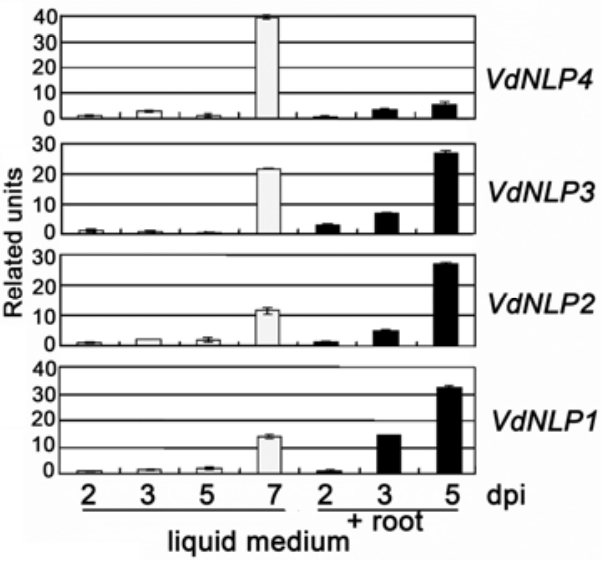

Fig. 5. Detection of expression of Verticillium dahliae necrosis- and ethylene-inducing protein (Nep1)-like protein $(V d N L P)$ transcripts. A, RNA gel blot analysis with total RNAs extracted from hyphae and spores collected from liquid Czapek-Dox medium (with and without cotton roots) at indicated time points. ${ }^{32} \mathrm{P}$-labeled $V d N L P$ gene-specific DNA probes were used. Methylene blue-stained rRNA is shown as mRNA loading controls. $\mathbf{B}$, Detection of expression of $V d N L P$ transcripts by quantitative real-time reverse-transcriptase polymerase chain reaction (PCR). Quantification of $V d N L P$ transcripts relative to the constitutively expressed $\beta$-tubulin gene (DQ266153) of Verticillium dahliae is shown. Results were analyzed with the Bio-Rad quantitative PCR software. scriptase polymerase chain reaction (RT-PCR) (Fig. 5B). These results suggested that degressive nutrition in the liquid medium and components of cotton root triggered the expression of both $V d N L P$ transcripts. Other $V d N L P$ transcripts were also examined in the parallel assay, and $V d N L P 3, V d N L P 4, V d N L P 7$, $V d N L P 8$ and $V d N L P 9$ showed expression patterns similar to those $V d N L P 1$ and $V d N L P 2$ (Fig. 5A and B) with higher or lower levels but the expression of VdNLP5 and VdNLP6 was under the detectable level (data not shown).

\section{Both $V d N L P 1$ and $V d N L P 2$ are dispensable for $V$. dahliae infection in cotton plants.}

The necrotic activity and induction of cotton leaf wilting of VdNLP1 and VdNLP2 prompted us to investigate a functional role for both VdNLP during plant pathogenesis. $V$. dahliae gene deletion mutant strains were generated by Agrobacterium spp.-mediated transformation and homologous recombination. Twenty individual sulfonylurea-resistant homologous recombinants of $V d N L P 1$ and $V d N L P 2$, purified by single-spore isolation, were obtained based on PCR screening. Two mutant strains of each gene (vdnlp1-1, vdnlp1-2, vdnlp2-1, and $v d n l p 2-2)$ were selected for further analysis. The successful targeted gene deletion of $V d N L P 1$ or $V d N L P 2$ in each independent transformant was confirmed by genomic DNA gel blot analysis (Fig. 6A and B). There were no $V d N L P 1$ or $V d N L P 2$ transcript signals detected in any of the mutant strains by RNA gel blot analysis (Fig. 6C). The $v d n l p 1 / v d n l p 2$ double mutant was also created, using another hygromycin-resistant vector for $V d N L P 2$ homologous recombination on the sulfonylurea-resistant $v d n l p 1-1$ background (Fig. 6D). The successful targeted deletion of both genes in the vdnlpl/vdnlp2 double mutant was confirmed by genomic DNA gel blot analysis (Fig. 6E). Neither of the two $V d N L P$ transcripts was detected in the $v d n l p 1 / v d n l p 2$ double mutant by RNA gel blot analysis (Fig. 6F).

Twelve 2-week-old cotton seedlings were inoculated with spores from the $v d n l p 1, v d n l p 2$, or $v d n l p 1 / v d n l p 2$ mutants or wild-type V592 strains using the unimpaired root dip-inoculation method that we developed previously and that was confirmed to mimic natural infection conditions in cotton (Gao et al. 2010). The infection assay for each homologous recombinant colony was repeated at least three times. Leaf wilt, lost cotyledons, and, finally, whole seedlings dried out at approximately 4 weeks postinoculation were observed for both singlemutant and double-mutant strains, indistinguishable from the symptoms caused by V592 (Fig. 6G and H). This result indicated that neither VdNLP1 nor VdNLP2 plays a major role for the $V$. dahliae V592 virulence on cotton plants.

\section{DISCUSSION}

In this report, we cloned and identified nine potential NPP1 domain-containing NLP family members from the $V$. dahliae V592 strain, isolated from cotton that originated in Xinjiang, China, named VdNLP1 to VdNLP9. Among the nine VdNLP, only two of the encoding proteins, VdNLP1 and VdNLP2, which belonged to the type I class of NLP proteins, had the abilities to induce necrotic lesion formation and trigger immunity-associated responses in N. benthamiana, Arabidopsis, and cotton plants. Both VdNLP1 and VdNLP2 induced the leaf wilting of cotton seedling cotyledons. However, neither $V d N L P 1, V d N L P 2$, nor the double mutant affected the pathogenicity of $V$. dahliae V592 in cotton infection.

Both the necrosis-inducing and elicitor activities were found in VdNLP1 and VdNLP2 but neither of the two activities was found in the other VdNLP proteins (Fig. 2), suggesting that the biochemical components of VdNLP1 and VdNLP2 that medi- 
ated necrotic cell death overlapped with those that mediated the plant defense response. This conjecture was consistent with the recent NLP $_{\text {Pya }}$ crystal structure and functional study, which found that $\mathrm{NLP}_{\mathrm{Pya}}$-mediated phytotoxicity and plant defense gene expression shared identical fold requirements (Ottmann et al. 2009). An incomplete conserved heptapeptide GHRHDWE motif or a lack of the upstream sequence, including the two conserved cysteine and $\mathrm{NLP}_{\mathrm{Pya}} \mathrm{D} 93$ residues in type II VdNLP6 to VdNLP9 (Fig. 3), may be the main reason that several of these proteins lacked necrotic and elicitor activities. However, type I VdNLP3 and type II VdNLP4 and VdNLP5 contained the mentioned conserved motif and residues but were still incapable of inducing necrotic cell death and triggering plant defense responses. Using mutagenesisbased analyses for the conserved amino acids in VdNLP2 (Figs. 3 and 4), we found that conserved residues located in the crystal structure (Ottmann et al. 2009) in $\beta 2-, \beta 4-$, and $\beta 5$ - strands were also necessary for VdNLP2 necrosis-inducing activity (Fig. 4). Moreover, another two conserved glycine residues (G74 and G79) located between two conserved cysteine residues were also important for the necrosis-inducing activity (Fig. 4). The induction of leaf necrosis was not achieved by mutants of the type I protein VdNLP3, in which the only missing conserved VdNLP2 residue, W114, was replaced (data not shown), suggesting that, in addition to the conserved motif and residues, nonconserved amino acids might also subtly affect the close vicinity of the conserved residues in the tertiary structure and result in changes in the necrosis-inducing activity of the VdNLP protein. In fact, study on the crystal structure of NLP $_{\text {Pya }}$ reveals that mediating membrane disruption by NLP is required for the necrosis-inducing activity of NLP (Ottmann et al. 2009). A plausible model for a membrane attachment of $\mathrm{NLP}_{\text {Pya }}$ suggests that some nonconserved residues are also involved, with certain conserved residues, in constituting a
A

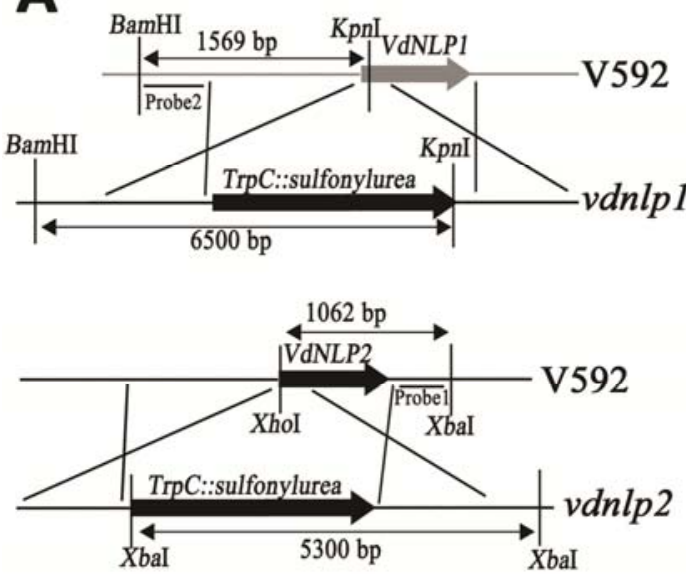

D

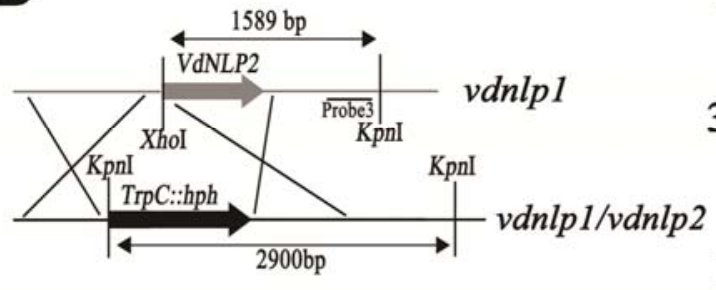

G

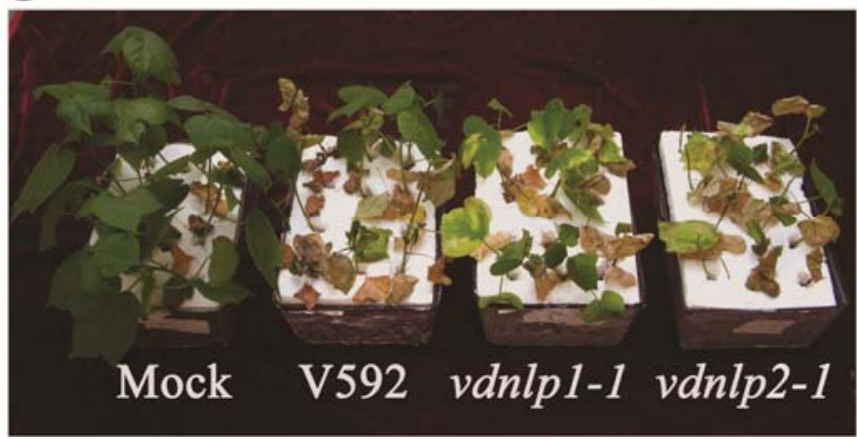

$1.0 \mathrm{~kb}-$
B

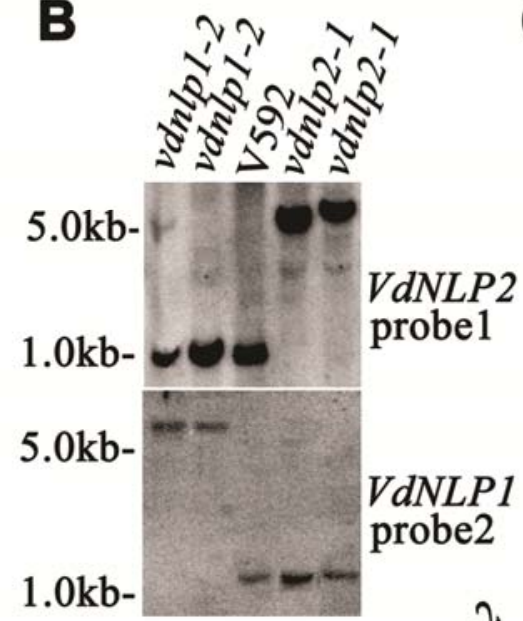

$1.0 \mathrm{~kb}-$<smiles>[CH-]</smiles>
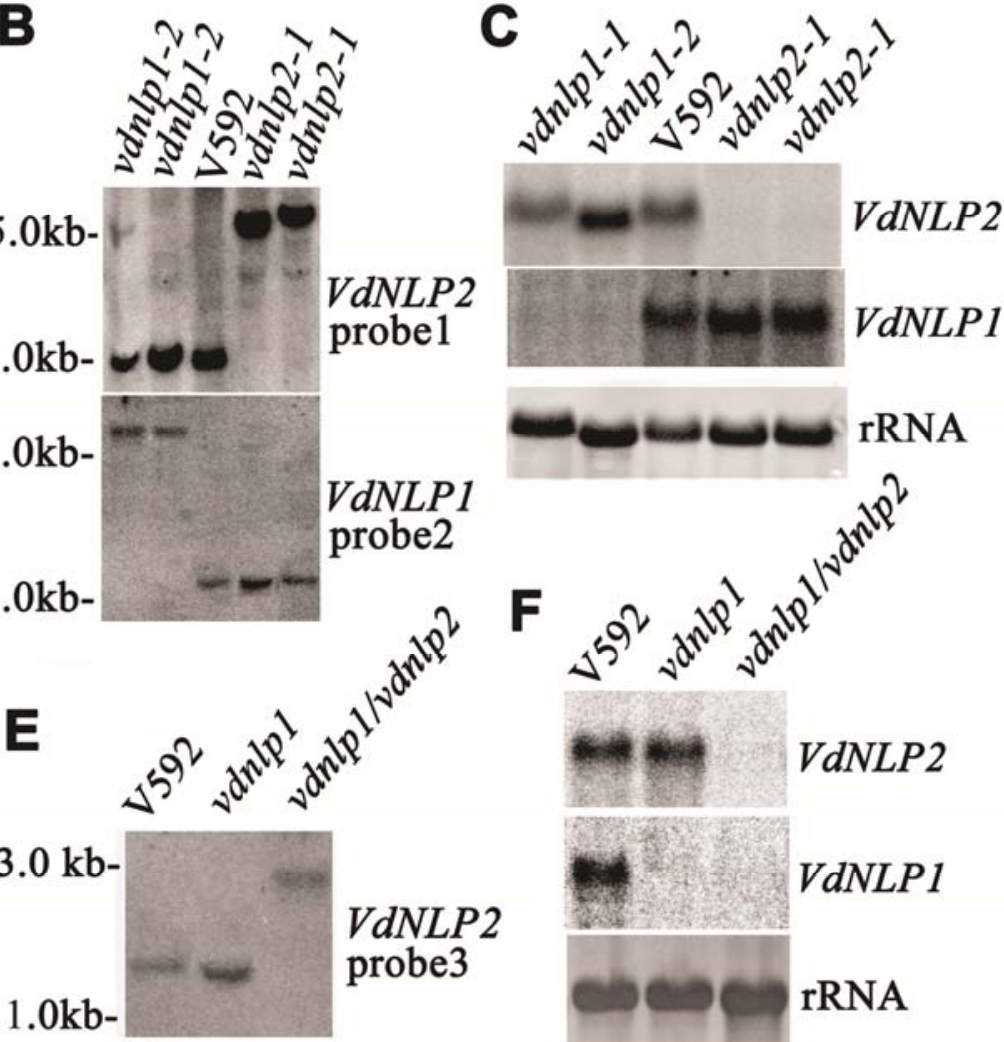

$\mathrm{H}$

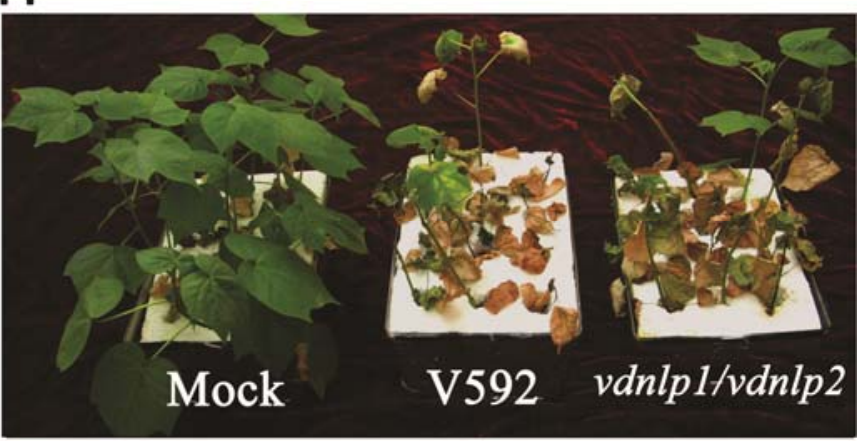

Fig. 6. Plant infection assays with single gene deletion mutants $v d n l p 1$ and $v d n l p 2$ and double-deletion mutant $v d n l p 1 / v d n l p 2$. A and D, Schematic representation of the homologous recombination event involved in the targeted replacement of Verticillium dahliae necrosis- and ethylene-inducing protein (Nep1)-like protein $(V d N L P) 1$ and $V d N L P 2$ with the TrpC::sulfonylurea or TrpC::hph resistance cassettes. The double-arrow line depicts the hybridization sites with the radio-labeled probes as indicated. B and $\mathbf{E}$, DNA gel blot analysis of successful gene replacement for $\mathbf{B}$, single-gene mutants and $\mathbf{E}$, doublegene mutants. ${ }^{32} \mathrm{P}$-labeled VdNLP gene-specific DNA probes were indicated in A and D. C and F, Conformation of gene knockout by RNA gel blot analysis. ${ }^{32} \mathrm{P}$-labeled $V d N L P$ gene-specific DNA probes were used. Methylene blue-stained rRNAs are shown as mRNA loading controls. G and $\mathbf{H}$, Disease symptoms of wild-type V592, single mutants, and double mutant on cotton plants. The photograph was taken at 4 weeks postinoculation. 
positively charged belt as the exposed side chains in the crystal structure that might interact with the polar head groups of membrane structures (Kufner et al. 2009).

Phytopathogenic microorganisms produce a wide range of cytolytic toxins that function as key virulence determinants (Glazebrook 2005; van't Slot and Knogge 2002). Numerous proteins have been identified that function either directly as toxins to induce plant cell death or in repressing or evading plant defense responses, thereby favoring early pathogen colonization (Espinosa and Alfano 2004; Friesen et al. 2008). Several NLP have shown a positive role in virulence (Amsellem et al. 2002; Mattinen et al. 2004; Pemberton et al. 2005). However, both VdNLP1 and VdNLP2 functioned as cytolytic toxins to induce necrotic cell death but both of them were dispensable for the pathogenicity of $V$. dahliae in cotton infection. In agreement with MgNLP that caused cytolysis and plant defense activation in Arabidopsis, the inactivation of the sole $M g N L P$ in $M$. graminicola did not affect its virulence (Motteram et al. 2009).

$N L P$ genes expressed under certain conditions have been reported in several cases. In Erwinia carotovora, Nep was expressed only when the bacteria were grown on solid medium (Mattinen et al. 2004). One of the necrosis-inducing peptide encoding genes, SsNep2, from Sclerotinia sclerotiorum, was expressed soon after the contact of the mycelium with plant leaf or other solid surfaces (Bashi et al. 2010). In the hemibiotrophic fungus Moniliophthora perniciosa, the NLP gene was expressed during the biotrophic stage (Garcia et al. 2007). Moreover, the peak expression of the MgNLP in Mycosphaerella graminicola was observed during the immediate presymptomatic phase of the colonization of susceptible wheat leaves, followed by a dramatic decrease during subsequent disease lesion development (Motteram et al. 2009). In another hemibiotrophic pathogen, Phytophthora sojae, the highest level of Nep gene expression coincided with the transition from the biotrophic to the necrotrophic stage (Qutob et al. 2006). The complexity of the symptom development process of $V$. dahliae infection, which initiates via the colonization of cotton roots, then progresses to the colonization of the vascular tissues and, subsequently, attacks the aerial parts of the cotton plant, made it difficult to predict the precise time point of the increased expression of the $V d N L P$ in infected cotton roots relative to the stages of symptom development. However, the greatly increased expression of $V d N L P 1$ and $V d N L P 2$ in liquid medium at 7 dpi revealed that the malnutrition or anoxic stress environment condition stimulated the expression of both genes. Together with the additional increased expression of both genes triggered by the presence of cotton roots in liquid medium and with the observation that both $V d N L P 1$ and $V d N L P 2$ genes were not required for V592 infection, we proposed that the $V d N L P$ were increased in expression when an environmental niche was deteriorated in the cotton organism, in a period triggering this hemibiotrophic phytopathogenic fungus to transition from the biotrophic to the necrotrophic stage. The accumulation of the other five $V d N L P$ transcripts was also detected. VdNLP3, VdNLP4 and VdNLP8 expressed at higher levels and showed induced expression patterns similar to those of $V d N L P 1$ and $V d N L P 2$, although their encoding proteins had noncytolytic activity. In fact, the obligate biotroph oomycete, Hyaloperonospora arabidopsidis, produces at least three NLP proteins, none of which proved to be cytolytic (Cabral et al. 2012). NLP genes have also been found in nonpathogenic organisms such as Vibrio pommerensis (Jores et al. 2003). Interestingly, a study on SsNep2 found that the lack of SsNep2 expression often coincided with a reduced virulence or a loss of pathogenicity; however, certain pharmacological treatments reduced $S s N e p 2$ expression without any apparent effect on virulence (Bashi et al. 2010), suggesting the existence of pleiotropic effects on and of the expression of SsNep2. We proposed that certain VdNLP might also play roles as elicitors that might contribute to the lack of aggressive host responses. Plants that develop non-overreactive responses to pathogen noncytolytic activity effectors may avoid or reduce disaster by infection with microorganisms that prefer hemibiotrophic or necrotrophic lifestyles. The further investigation of NLP with noncytolytic activity will be helpful in addressing this issue.

\section{MATERIALS AND METHODS}

Fungal isolates, culture conditions, and infection assays.

A virulent defoliating Verticillium dahliae isolate V592 from cotton originated in Xinjiang, China, was used in this study. This isolate and its transformants were stored at $-80^{\circ} \mathrm{C}$ in the form of microconidial suspension in $20 \%$ glycerol. Cultures were reactivated on potato dextrose agar (PDA) medium (Becton, Dickinson and Company, Franklin Lakes, NJ, U.S.A.). Conidia production for infection assays and germination tests were cultured in liquid Czapek-Dox medium (sucrose at 30 g/liter, $\mathrm{NaNO}_{3}$ at $3 \mathrm{~g} /$ liter, $\mathrm{MgSO}_{4}-7 \mathrm{H}_{2} \mathrm{O}$ at $0.5 \mathrm{~g} /$ liter, $\mathrm{KCl}$ at $0.5 \mathrm{~g} / \mathrm{liter}, \mathrm{FeSO}_{4}-7 \mathrm{H}_{2} \mathrm{O}$ at $100 \mathrm{mg} / \mathrm{liter}$, and $\mathrm{K}_{2} \mathrm{HPO}_{4}$ at 1 $\mathrm{g} /$ liter, $\mathrm{pH}$ 7.2).

For plant infection, cotton plants ('Xinluzao No. 16') were used in infection assays to evaluate the effect of $V$. dahliae isolate V592 and transformants on virulence. Transformants generated from V592 were evaluated for their virulence on cotton (Xinluzao No. 16), using our laboratory unimpaired root-dip inoculation method, as described in our previous research (Gao et al. 2010). Disease progress was recorded over time for the 2 months of the experiment period. Disease severity was counted by the percentage of leaves that showed wilting symptom at each time point. The infection assay for each mutant colony was repeated at least three times.

\section{Generation of an amino acid phylogenetic tree for NLP.}

All amino acid sequences detailed in the legend of Figure 1 were retrieved from either the JGI or Broad websites. The sequences were aligned using ClustalW and then analyzed using the phylogenetics package MEGA4 (Tamura et al. 2007). The tree was obtained using neighbor analysis with 1,000 bootstrap replications.

\section{DNA cloning and plasmid construction.}

For obtaining the full-length cDNA sequence of nine VdNLP proteins, $3^{\prime}$ rapid amplification of cDNA ends (RACE) was performed according to the manufacturer's instructions (First Choice RLM-RACE Kit; Ambion, Austin, TX, U.S.A.). Primers for $3^{\prime}$ RACE are shown in Supplementary Table S1. The open reading frame sequences of nine genes were amplified from the correct clones with primers and then were ligated into the pGEM-T Easy vector (Tiangen, Beijing) and were sequenced, giving pGEM-VdNLP plasmids. The correct clones were digested with the corresponding enzymes; then, cutting sites in primer sequences were underlined and cloned into pBI121 vector (Chen et al. 2003) for the infiltration assay of Agrobacterium spp.-mediated plant expression

The conserved amino acid mutants of VdNLP2 were produced by overlapping PCR as previously described (Fellbrich et al. 2002).

pCAMBIA1300-HPH-SUR, which contained a sulfonylurea resistance cassette, was generated as follows. The $h p h$ resistance cassette was amplified from the vector pBHT2 (Mullins et al. 2001) with related primers and ligated into the pGEM-T easy vector (Tiangen). The XhoI digestion fragment was in- 
serted into XhoI-digested pCAMBIA1300 (Hajdukiewicz et al. 1994), giving pCAMBIA1300-HPH with expression of $H P H$

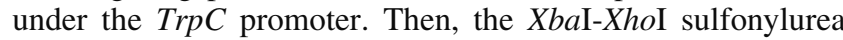
resistance cassette from pSULPH-GFP (Gao et al. 2010) conferring resistance to chlorimuron-ethyl was inserted into XbaI/SalI-digested pCAMBIA1300-HPH, giving pCAMBIA1300-HPH-SUR vector.

To generate the pCAMBIA1300-HPH-SUR-VdNLP1 and pCAMBIA1300-HPH-SUR-VdNLP2 for homologous recombination based on the wild-type V592 strain, flanking genomic DNA sequences of either side of the $V d N L P 1$ and $V d N L P 2$ genes were amplified with primers. VdNLP1flank1, VdNLP1 flank2, $V d N L P 2$ flank1, and $V d N L P 2$ flank2 were inserted into the flank of the sulfonylurea resistance cassette of the vector pCAMBIA1300-HPH-SUR. The $h p h$ resistance cassette is useful for the accessorial selection of the homologous recombinations. Successful recombinants should have no resistance to the hygromycin.

To generate the pCAMBIA1300-GFP-HPH-VdNLP2 vector for VdNLP2 homologous recombination based on the $v d n l p 1-1$ strain, $V d N L P 2$ flank1 and $V d N L P 2$ flank2 were each cloned into either flank of the $h p h$ resistance cassette of pCAMBIA1300-HPH to obtain pCAMBIA1300-HPH-VdNLP2. The HindIII-XbaI green fluorescent protein (GFP) cassette with the ToxA promoter was excised from pSULPH-GFP (Gao et al. 2010) and cloned into pCAMBIA1300-HPH-VdNLP2 to obtain pCAMBIA1300-GFP-HPH-VdNLP2. The GFP cassette is useful for the accessorial selection of the $v d n l p 1 / v d n l p 2$ homologous recombinations. Successful recombinants should have no GFP fluorescence. Fungal transformation (Gao et al. 2010) was used by Agrobacterium EHA105 containing each of these three plasmids.

\section{Protein expressions in Escherichia coli.}

The cDNAs of nine VdNLP without signal peptide were amplified with primers. The PCR product was inserted into pET28a (+) (Novagen, Madison, WI, U.S.A.), giving pET-HisVdNLP plasmids. Escherichia coli BL 21(DE3) containing each of these plasmids was used to express the related His-tag fusion proteins by induction with $0.1 \mathrm{mM}$ isopropyl-1-thio- $\beta$ D-galactopyranoside. Proteins were examined by sodium dodecyl sulfate polyacrylamide gel electrophoresis. Protein purification was performed with the Ni-nitrilotriacetic acid resin (Qiagen, Valencia, CA, U.S.A.) according to the manufacturer's instructions; then, the purified proteins were dialyzed against a phosphate-buffered saline (PBS) buffer $(\mathrm{pH} \mathrm{7.4)} \mathrm{at}$ $4^{\circ} \mathrm{C}$. The protein concentrations were determined with the BioRad (Hercules, CA, U.S.A.) protein assay kit according to the manufacturer's instructions.

\section{Agrobacterium and protein infiltration assays.}

The infiltration assay of Agrobacterium spp.-mediated plant transient expression was performed with a culture of Agrobacterium EHA105 carrying related constructs (optical density at $600 \mathrm{~nm}=2.5$ ) on leaves of $N$. benthamiana (30 days old) as previously described (Ying et al. 2010).

Protein infiltration experiments were performed using pressure infiltration with a syringe without a needle with protein at $0.05 \mu \mathrm{g} / \mu \mathrm{l}$ on leaves of $N$. benthamiana ( 30 days old), Arabidopsis thaliana ecotype Col-0 (14 days old), or cotton cotyledons and hypocotyls (10 days old). Lesion formation or wilting symptoms were viewed and photographed each day after treatment. Leaf tissues were excised at various time points after infiltration and stored at $-80^{\circ} \mathrm{C}$ for RNA isolation.

To view $\mathrm{H}_{2} \mathrm{O}_{2}$ produced in plant leaves, treated leaf samples were incubated for $8 \mathrm{~h}$ with 3,3-diaminobenzidine solution at 1 $\mathrm{mg} / \mathrm{ml}, \mathrm{pH} 7.5$, and then decolorized in $95 \%$ ethanol. The sam- ple was mounted on a slide with $60 \%$ glycerol and examined under a light microscope. $\mathrm{H}_{2} \mathrm{O}_{2}$ was detected as reddish-brown coloration.

\section{Nucleic acid extraction and blotting.}

Fungal isolates were grown in the liquid Czapek-Dox medium for 2 to 7 days with shaking at $200 \mathrm{rpm}, 26^{\circ} \mathrm{C}$, in dark conditions, and the resulting mycelium was harvested for DNA and RNA isolation and hybridization as previously described (Gao et al. 2010). The gene-specific DNA probes NbPR-5 (X03913.1), NbPR-1a (X06361.1), osmotin(AF304007.1), CAD1-C1(AF174294.1), AtPRl (NM_127025.2), AtACS6 (NM_117199.1), AtPDF1.2 (NM_123809.3), VdNLP1, VdNLP2, VdNLP3, $V d N L P 4, V d N L P 7, V d N L P 8$, and $V d N L P 9$, were amplified with related primers.

\section{Agrobacterium spp.-mediated targeted gene deletion.}

Fungal targeted gene deletion used Agrobacterium spp.mediated transformation as previously described (Gao et al. 2010). Individual transformants of VdNLP1 and VdNLP2 homologous recombinants based on the V592 strain were transferred into PDA medium containing hygromycin B or chlorimuron-ethy1 and incubated until conidiogenesis. Individual successful transformants should have normal development in PDA medium containing chlorimuron-ethy 1 but be killed in PDA medium containing hygromycin B $(75 \mu \mathrm{g} / \mathrm{ml}) . V d N L P 2$ homologous recombinants based on the $v d n l p 1-1$ strain were detected with the fluorescence microscope. Individual successful transformants of double mutants should have no fluorescence. Homologous recombinants were further verified by DNA and RNA blot analysis. Conidia of individual transformants were suspended with sterile water and plated on PDA medium. Spores from these monoconidial cultures were stored in $20 \%$ glycerol at $-80^{\circ} \mathrm{C}$ until further analysis.

\section{Preparation of a crude elicitor mixture of $\boldsymbol{V}$. dahliae.}

Total elicitors secreted by $V$. dahliae during culture were prepared as previously described (Buchner et al. 1982; Wang et al. 2004). Briefly, $\left(\mathrm{NH}_{4}\right)_{2} \mathrm{SO} 4$ was added to the culture fluid to $80 \%$ saturation, mixed well, and left to stand at $4{ }^{\circ} \mathrm{C}$ overnight. The solution was centrifuged at $10,000 \times g$ for $30 \mathrm{~min}$, and the pellet was dissolved in PBS buffer and dialyzed at $4^{\circ} \mathrm{C}$.

\section{Quantitative real-time RT-PCR reaction.}

Transcription levels of $V d N L P$ were examined in wild-type V592 strains grown in liquid Czapek-Dox medium supplemented with or without fresh cotton roots. RNA extraction and cDNA synthesis were described above. A quantitative (q)PCR reaction was performed using first-strand cDNAs as a template and the QuantiFast SYBR Green PCR (Qiagen) master mix. Gene-specific primers were designed for $V d N L P$. qPCR reactions were performed in duplicate and, for data analysis, average threshold cycle values were calculated for each gene on the basis of three independent biological samples. Transcription levels of the target genes were quantified relative to the constitutively expressed $\beta$-tubulin gene (DQ266153) that was amplified with primers VdBt-RT-F and VdBt-RT-R. qPCR was performed in a Bio-Rad CFX96 Real-Time system. The results were analyzed with the BioRad qPCR software. PCR cycling started with an initial step of denaturation at $95^{\circ} \mathrm{C}$ for $3 \mathrm{~min}$, followed by 40 cycles of $95^{\circ} \mathrm{C}$ for $10 \mathrm{~s}$ and $60^{\circ} \mathrm{C}$ for $20 \mathrm{~s}$.

\section{ACKNOWLEDGMENTS}

This research was supported by grants from the Chinese Academy of Sciences (Knowledge Innovation Program KSCX2-EW-N-06), the Ministry 
of Science and Technology (2011CB100700), and the China Transgenic Research and Commercialization Key Special Project (2009ZX08010001B).

\section{LITERATURE CITED}

Amsellem, Z., Cohen, B. A., and Gressel, J. 2002. Engineering hypervirulence in a mycoherbicidal fungus for efficient weed control. Nat. Biotechnol. 20:1035-1039.

Bae, H., Kim, M. S., Sicher, R. C., Bae, H. J., and Bailey, B. A. 2006. Necrosis- and ethylene-inducing peptide from Fusarium oxysporum induces a complex cascade of transcripts associated with signal transduction and cell death in Arabidopsis. Plant Physiol. 141:1056-1067.

Bailey, B. A. 1995. Purification of a protein from culture filtrates of Fusarium oxysporum that induces ethylene and necrosis in leaves of Erythroxylum coca. Phytopathology 85:1250-1255.

Bashi, Z. D., Khachatourians, G., and Hegedus, D. D. 2010. Isolation of fungal homokaryotic lines from heterokaryotic transformants by sonic disruption of mycelia. BioTechniques 48:41-46.

Bowman, D. 1999. Public cotton breeders-do we need them? J. Cotton Sci. 3:139-152.

Buchner, V., Nashmias, A., and Burstein, Y. 1982. Isolation and partial characterization of a phytotoxic glycopeptide from a protein-lipopolysaccharide complex produced by a potato isolate of Verticillium dahliae. FEBS (Fed. Eur. Biochem. Soc.) Lett. 138:261-264.

Cabral, A., Oome, S., Sander, N., Küfner, I., Nürnberger, T., and Van den Ackerveken, G. 2012. Nontoxic Nep1-like proteins of the downy mildew pathogen Hylaloperonospora arabidopsidis: Repression of necrosis-inducing activity by a surface-exposed region. Mol. Plant-Microbe Interact. 25:697-708

Chen, P. Y., Wang, C. K., Soong, S. C., and To, K. Y. 2003. Complete sequence of the binary vector pBI121 and its application in cloning TDNA insertion from transgenic plants. Mol. Breed. 11:287-293.

Chisholm, S. T., Coaker, G., Day, B., and Staskawicz, B. J. 2006. Host-microbe interactions: Shaping the evolution of the plant immune response. Cell 124:803-814.

Dean, R. A., Talbot, N. J., Ebbole, D. J., Farman, M. L., Mitchell, T. K., Orbach, M. J., Thon, M., Kulkarni, R., Xu, J. R., Pan, H., Read, N. D., Lee, Y. H., Carbone, I., Brown, D., Oh, Y. Y., Donofrio, N., Jeong, J. S., Soanes, D. M., Djonovic, S., Kolomiets, E., Rehmeyer, C., Li, W., Harding, M., Kim, S., Lebrun, M. H., Bohnert, H., Coughlan, S., Butler, J., Calvo, S., Ma, L. J., Nicol, R., Purcell, S., Nusbaum, C., Galagan, J. E., and Birren, B. W. 2005. The genome sequence of the rice blast fungus Magnaporthe grisea. Nature 434:980-986.

Espinosa, A., and Alfano, J. R. 2004. Disabling surveillance: Bacterial type III secretion system effectors that suppress innate immunity. Cell. Microbiol. 6:1027-1040.

Fellbrich, G., Blume, B., Brunner, F., Hirt, H., Kroj, T., Ligterink, W., Romanski, A., and Nurnberger, T. 2000. Phytophthora parasitica elicitor-induced reactions in cells of Petroselinum crispum. Plant Cell Physiol. 41:692-701.

Fellbrich, G., Romanski, A., Varet, A., Blume, B., Brunner, F., Engelhardt, S., Felix, G., Kemmerling, B., Krzymowska, M., and Nurnberger, T. 2002. NPP1, a Phytophthora-associated trigger of plant defense in parsley and Arabidopsis. Plant J. 32:375-390.

Friesen, T. L., Faris, J. D., Solomon, P. S., and Oliver, R. P. 2008. Hostspecific toxins: Effectors of necrotrophic pathogenicity. Cell. Microbiol. 10:1421-1428.

Gao, F., Zhou, B. J., Li, G. Y., Jia, P. S., Li, H., Zhao, Y. L., Zhao, P., Xia, G. X., and Guo, H. S. 2010. A glutamic acid-rich protein identified in Verticillium dahliae from an insertional mutagenesis affects microsclerotial formation and pathogenicity. PloS One 5:e15319.

Garcia, O., Macedo, J. A., Tiburcio, R., Zaparoli, G., Rincones, J., Bittencourt, L. M., Ceita, G. O., Micheli, F., Gesteira, A., Mariano, A. C., Schiavinato, M. A., Medrano, F. J., Meinhardt, L. W., Pereira, G. A., and Cascardo, J. C. 2007. Characterization of necrosis and ethyleneinducing proteins (NEP) in the basidiomycete Moniliophthora perniciosa, the causal agent of witches' broom in Theobroma cacao. Mycol. Res. 111:443-455.

Gijzen, M., and Nurnberger, T. 2006. Nep1-like proteins from plant pathogens: Recruitment and diversification of the NPP1 domain across taxa. Phytochemistry 67:1800-1807.

Glazebrook, J. 2001. Genes controlling expression of defense responses in Arabidopsis-2001 status. Curr. Opin. Plant Biol. 4:301-308.

Glazebrook, J. 2005. Contrasting mechanisms of defense against biotrophic and necrotrophic pathogens. Annu. Rev. Phytopathol. 43:205-227.

Hajdukiewicz, P., Svab, Z., and Maliga, P. 1994. The small, versatile pPZP family of Agrobacterium binary vectors for plant transformation. Plant Mol. Biol. 25:989-994.
Hammond-Kosack, K. E., and Jones, J. G. D. 1996. Resistance genedependent plant defense response. Plant Cell Physiol. 8:1773-1791.

Jennings, J. C., Birkhold, P. C., Mock, N. M., Baker, C. J., Anderson, J. D., and Bailey, B. A. 2001. Induction of defense responses in tobacco by the protein Nep1 from Fusarium oxysporum. Plant Sci. 161:891899.

Jores, J., Appel, B., and Lewin, A. 2003. Cloning and molecular characterization of a unique hemolysin gene of Vibrio pommerensis sp. nov.: Development of a DNA probe for the detection of the hemolysin gene and its use in identification of related Vibrio spp. from the Baltic Sea. FEMS (Fed. Eur. Microbiol. Soc.) Microbiol. Lett. 229:223-229.

Kamoun, S. 2006. A catalogue of the effector secretome of plant pathogenic oomycetes. Annu. Rev. Phytopathol. 44:41-60.

Keen, N. T., Long, M., and Erwin, D. C. 1972. Possible involvement of pathogen-produced protein-lipopolysaccharide complex in Verticillium wilt of cotton. Physiol. Plant Pathol. 2:317-331.

Klosterman, S. J., Subbarao, K. V., Kang, S., Veronese, P., Gold, S. E., Thomma, B. P., Chen, Z., Henrissat, B., Lee, Y. H., Park, J., GarciaPedrajas, M. D., Barbara, D. J., Anchieta, A., de Jonge, R., Santhanam, P., Maruthachalam, K., Atallah, Z., Amyotte, S. G., Paz, Z., Inderbitzin, P., Hayes, R. J., Heiman, D. I., Young, S., Zeng, Q., Engels, R. Galagan, J., Cuomo, C. A., Dobinson, K. F., and Ma, L. J. 2011. Comparative genomics yields insights into niche adaptation of plant vascular wilt pathogens. PLoS Pathog. 7:e1002137.

Koroleva, O. V., Stepanova, E. V., Gavrilova, V. P., Biniukov, V. I., and Pronin, A. M. 2001. Comparative characterization of methods for removal of $\mathrm{Cu}(\mathrm{II})$ from the active sites of fungal laccases. Biochemistry 66:960-966.

Kufner, I., Ottmann, C., Oecking, C., and Nurnberger, T. 2009. Cytolytic toxins as triggers of plant immune response. Plant Signal. Behav. 4:977-979.

Lindeberg, M., Myers, C. R., Collmer, A., and Schneider, D. J. 2008. Roadmap to new virulence determinants in Pseudomonas syringae: Insights from comparative genomics and genome organization. Mol. Plant-Microbe Interact. 21:685-700.

Liu, J., Benedict, C. R., Stipanovic, R. D., and Bell, A. A. 1999. Purification and characterization of $S$-adenosyl-L-methionine: Desoxyhemigossypol-6-O-methyltransferase from cotton plants. An enzyme capable of methylating the defense terpenoids of cotton. Plant Physiol. 121:1017-1024.

Luo, P., Wang, Y. H., Wang, G. D., Essenberg, M., and Chen, X. Y. 2001. Molecular cloning and functional identification of (+)-delta-cadinene-8 hydroxylase, a cytochrome P450 mono-oxygenase (CYP706B1) of cotton sesquiterpene biosynthesis. Plant J. 28:95-104

Mattinen, L., Tshuikina, M., Mae, A., and Pirhonen, M. 2004. Identification and characterization of Nip, necrosis-inducing virulence protein of Erwinia carotovora subsp. carotovora. Mol. Plant-Microbe Interact. 17:1366-1375.

Meng, Y. L., Jia, J. W., Liu, C. J., Liang, W. Q., Heinstein, P., and Chen, X. Y. 1999. Coordinated accumulation of (+)-delta-cadinene synthase mRNAs and gossypol in developing seeds of Gossypium hirsutum and a new member of the cad1 family from $G$. arboreum. J. Nat. Prod. $62: 248-252$.

Motteram, J., Kufner, I., Deller, S., Brunner, F., Hammond-Kosack, K. E., Nurnberger, T., and Rudd, J. J. 2009. Molecular characterization and functional analysis of MgNLP, the sole NPP1 domain-containing protein, from the fungal wheat leaf pathogen Mycosphaerella graminicola. Mol. Plant-Microbe Interact. 22:790-799.

Mullins, E. D., Chen, X., Romaine, P., Raina, R., Geiser, D. M., and Kang, S. 2001. Agrobacterium-mediated transformation of Fusarium oxysporum: An efficient tool for insertional mutagenesis and gene transfer. Phytopathology 91:173-180.

Nachmias, A., Büchner, V., and Krikun, J. 1982. Differential diagnosis of Verticillium dahliae in potato with antisera to partially purified pathogen-produced extracellular antigens. Potato Res. 25:321-328.

Nachmias, A., Buchner, V., and Burstein, Y. 1985. Biological and immunochemical characterization of a low molecular weight phytotoxin isolated from a protein-lipopolysaccharide complex produced by a potato isolate of Verticillium dahliae Kleb. Physiol. Plant Pathol. 26:43-55.

Nachmias, A., Buchner, V., Tsror, L., Burstein, Y., and Keen, N. 1987. Differential phytotoxicity of peptides from culture fluids of Verticillium dahliae races 1 and 2 and their relationship to pathogenicity of the fungi on tomato. Phytopathology 77:506-510.

Ottmann, C., Luberacki, B., Kufner, I., Koch, W., Brunner, F., Weyand, M., Mattinen, L., Pirhonen, M., Anderluh, G., Seitz, H. U., Nurnberger, T., and Oecking, C. 2009. A common toxin fold mediates microbial attack and plant defense. Proc. Natl. Acad. Sci. U.S.A. 106:10359-10364.

Pegg, G. F. 1989. Pages 51-94 in: Pathogenesis in Vascular Disease of Plants. Springer-Verlag, Berlin.

Pemberton, C. L., and Salmond, G. P. 2004. The Nep1-like proteins-A 
growing family of microbial elicitors of plant necrosis. Mol. Plant Pathol. 5:353-359.

Pemberton, C. L., Whitehead, N. A., Sebaihia, M., Bell, K. S., Hyman, L. J., Harris, S. J., Matlin, A. J., Robson, N. D., Birch, P. R., Carr, J. P., Toth, I. K., and Salmond, G. P. 2005. Novel quorum-sensing-controlled genes in Erwinia carotovora subsp. carotovora: Identification of a fungal elicitor homologue in a soft-rotting bacterium. Mol. Plant-Microbe Interact. 18:343-353.

Qutob, D., Kemmerling, B., Brunner, F., Kufner, I., Engelhardt, S., Gust, A. A., Luberacki, B., Seitz, H. U., Stahl, D., Rauhut, T., Glawischnig, E., Schween, G., Lacombe, B., Watanabe, N., Lam, E., Schlichting, R., Scheel, D., Nau, K., Dodt, G., Hubert, D., Gijzen, M., and Nurnberger, T. 2006. Phytotoxicity and innate immune responses induced by Nep1like proteins. Plant Cell 18:3721-3744.

Sato, T., and Theologis, A. 1989. Cloning the mRNA encoding 1-aminocyclopropane-1-carboxylate synthase, the key enzyme for ethylene biosynthesis in plants. Proc. Natl. Acad. Sci. U.S.A. 86:6621-6625.

Schnathorst, W. C., and Mathre, D. E. 1966. Host range and differentiation of a severe form of Verticillium albo-atrum in cotton. Phytopathology 56:1155-1161.

Schouten, A., van Baarlen, P., and van Kan, J. A. 2008. Phytotoxic Nep1-like proteins from the necrotrophic fungus Botrytis cinerea associate with membranes and the nucleus of plant cells. New Phytol. 177:493-505.

Staats, M., van Baarlen, P., Schouten, A., and van Kan, J. A. L. 2007. Functional analysis of NLP genes from Botrytis elliptica. Mol. Plant Pathol. 8:209-214.

Tamura, K., Dudley, J., Nei, M., and Kumar, S. 2007. MEGA4: Molecular
Evolutionary Genetics Analysis (MEGA) software version 4.0. Mol. Biol. Evol. 24:1596-1599.

van't Slot, K. A. E., and Knogge, W. 2002. A dual role for microbial pathogen-derived effector proteins in plant disease and resistance. Crit. Rev. Plant Sci. 21:229-271.

Veit, S., Worle, J. M., Nurnberger, T., Koch, W., and Seitz, H. U. 2001. A novel protein elicitor (PaNie) from Pythium aphanidermatum induces multiple defense responses in carrot, Arabidopsis, and tobacco. Plant Physiol. 127:832-841.

Wang, J. Y., Cai, Y., Gou, J. Y., Mao, Y. B., Xu, Y. H., Jiang, W. H., and Chen, X. Y. 2004. VdNEP, an elicitor from Verticillium dahliae, induces cotton plant wilting. Appl. Environ. Microbiol. 70:4989-4995.

Xia, Z., Achar, P. N., and Gu, B. 1998. Vegetative compatibility groupings of Verticillium dahliae from cotton in mainland China. Eur. J. Plant Pathol. 104:871-876.

Ying, X. B., Dong, L., Zhu, H., Duan, C. G., Du, Q. S., Lv, D. Q., Fang, Y Y., Garcia, J. A., Fang, R. X., and Guo, H. S. 2010. RNA-dependent RNA polymerase 1 from Nicotiana tabacum suppresses RNA silencing and enhances viral infection in Nicotiana benthamiana. Plant Cell $22: 1358-1372$.

\section{AUTHOR-RECOMMENDED INTERNET RESOURCE}

Broad Institute Verticillium group database: www.broad.mit.edu/annotation/genome/verticillium_dahliae/MultiHome. html 